\title{
Effect of Housing Relocation Subsidy Policy on Energy Consumption: A Simulation Case Study
}

\author{
Yanhong Yin a, b, *, Kohei Aikawa ${ }^{\mathrm{c}}$, Shoshi Mizokami ${ }^{\mathrm{d}, *}$ \\ ${ }^{a}$ Faculty of Maritime and Transportation, Ningbo University, 818 Fenghua Road, Jiangbei \\ District, Ningbo 315211, China \\ b National Traffic Management Engineering \& Technology Research Centre Ningbo University \\ Sub-center in China, 818 Fenghua Road, Jiangbei District, Ningbo 315211, China \\ ${ }^{\mathrm{c}}$ Obayashi Corporation, Konan 2-15-2, Minato-ku, Tokyo107-0062, Japan \\ ${ }^{\mathrm{d}}$ Department of Civil and Environmental Engineering, Kumamoto University, 2-39-1, Kurokami, \\ Kumamoto 8608555, Japan \\ *Corresponding author. Tel: +86 5748760 9546; Email: yinyanhong@nbu.edu.cn (Yanhong \\ Yin); +81 96342 3541; Email: smizo@gpo.kumamoto-u.ac.jp (Shoshi Mizokami).
}




\begin{abstract}
This study investigates the effect of housing relocation policies on energy consumption by simulating relocation choice and household consumption behaviors. Energy consumption is estimated based on consumption behaviors. Three types of policy are analyzed: the relocation subsidy policy, the suburban residence taxation policy, and the combination of subsidy and taxation policy. The results show that all policies have influence on housing relocation choice and consumption behaviors. The number of households in a given area would increase by two percent under the relocation subsidy policy. However, this type of policy contributes to greater demand of general goods, land, and energy consumption. A suburban residence taxation policy shows a very limited effect on housing relocation choice behavior, with only a 0.1 percent increase in households in the designated area. However, this policy shows a strong effect on energy reduction due to shorter trip time and less demand of car trips and land. A combination of subsidy policy and suburban residence taxation policy attracts 2.2 percent of household moves to the city center area. Energy consumption increases as consumption of general goods increases.
\end{abstract}

Keywords: Energy consumption; Housing relocation choice; Consumption behavior; Subsidy policy; Taxation policy 


\section{Introduction}

The magnitude and speed of urban growth have made urban development a crucial element affecting the long-term outlook of civilization. Along with climate change and energy security, issues such as the growth of cities in developing countries and the depopulation of central areas in cities have become serious concerns. Significant shifts of land use and travel behaviors in cities have been noticed in recent decades. Increasing income and vehicle ownership have made it possible for many families to find housing in suburban areas and travel longer distances, resulting in less transit usage and the decentralization of metropolitan areas [1].

A global urban renovation process of radically transforming low-density urban zones has been started because there is an argument that efficient land use and land preservation are environmentally sensitive strategies. The pattern of lower-density development has been gradually substituted by compact development, which reduces costs through more efficient use of land and infrastructure. Strategies that lead to compact development have generated considerable research interest. Because one of the widely discussed aspects of compact development in the context of urban sustainability relates to urban structure, or urban form $[2,3]$, many studies recommend a compact urban structure $[4,5,6]$. The structure encourages high density, mixed land use, efficient public transport systems, and dimensions that encourage walking and cycling [4]. It is believed that less private car dependency and the preservation of green fields and arable land are two major benefits of a compact urban structure. Lower residential energy requirements could be expected in the more compact urban structures, as densely settled areas have more shared walls, smaller living space per capita and, potentially, more efficient heating technology, such as district heating or natural gas [7, 8].

The term 'urban structure' covers aspects of density, geometric shape, land use (residential, industrial), and infrastructure (road, rail, waterway), with implications for indicators such as density, fragmentation and accessibility [9]. Researchers search for the proper index to represent the compact urban structure. Although more complex land use index would be desirable, they are very complicated to build. Land use index is mostly feasible for intra-city research and is rarely used in comparative studies. Population density can serve as a useful indicator of urban structure [8]. As the influence of land use and economic activities could be reflected by the population distribution, literature focuses on the analysis of population distribution to address the problem of compact development. The link between population density and household energy consumption has been supported by various urban energy studies, which have highlighted the importance of high population density as a factor to reduce transport energy consumption [10].

There is a wide spectrum of research analyzing the strategies for population distribution toward compact development. Broadly speaking, two major streams of studies can be identified. The first stream of literature estimates the initiative movement of populations by exploring the effects of policies or projects on population distribution by housing location modeling. Factors that influence housing location choice have been verified and models have been built to forecast housing locations. Modeling behaviors of residential location choice is a primary population distribution concern for urban planners, policymakers, and researchers. Residential location modeling can be traced back to the land use modeling by Von Thunen [11]. He explained the effect of transport costs on activity locations and the land market in an agricultural region. Alonso applied this model in a monocentric city and found that households choose their 
residential location by maximizing a utility function depending on their goods expenditures, land lot size, and distance to the city center [12]. Studies afterward described residential location choice by introducing the discrete modeling framework [13, 14]. This framework quantifies the impact of different residential location characteristics and their interactions with household characteristics. The preferences toward residential locations are sensitive to socioeconomic characteristics such as educational attainment, income, household tenure (rent or own), important life events (particularly childbirth), attitudes and environmental awareness [15, 16]. With detailed specification of location characteristics and housing units, households make the decision to choose the alternative that provides highest utility from a set of mutually exclusive alternatives.

The second stream of studies analyzes natural population movement by investigating household housing locations. Literature pays more attention on surveys to investigate residents' attitudes toward housing location [17, 18]. By analyzing the behaviors of residents who moved into high-density residential environments in the central area of Dublin, Howley found that most residents prefer lower-density locations, which call for more efforts toward the long-term success of urban intensification [19]. Using a large-scale household survey and aggregated census data from Beijing, Wu et al. developed a framework to empirically measure the relative impact of location characteristics versus individual characteristics in determining households' residential location choices. The accessibility of local public goods was found to be significant in determining households' location choices [20]. Torres et al. designed a stated-choice (SC) experiment to investigate the locational preferences of residents in Central Business District (CBD) in Santiago de Chile. Higher willingness to pay for accessibility and cleanliness of the neighborhood, and a lower valuation for attributes related to recreation (i.e., gym and pool or cultural services) were found [21]. Drawing upon a stated-preference survey in the Wasatch Front region in Utah, Liao et al. identified significant heterogeneity in residential location preferences over compact, walkable and transit-friendly neighborhoods. Compact development is highly accepted among families with fewer school-age children, low-income and renter-occupied households, and those who appreciate social heterogeneity and have less desire for privacy [22].

Previous studies performed deep investigations of residents' housing location behaviors. Initial attempts to estimate population relocation focus on identifying the factors of housing relocation and population movement. The methodology and findings are useful for forecasting the population distribution under various policies. However, most work only payed attention to residential location behavior, without considering the environmental outcome of behaviors. The effect of compact development policy on consumption behaviors of residents and energy consumption is often neglected or considered individually in previous literatures. Aiming for compact development and sustainable development, it is important to analyze not only the housing location but also the environmental outcome, such as energy consumption and greenhouse gas emission [23, 24, 25]. Because the goal of compact development is to preserve arable land and to reduce energy consumption and thus pollution, there remains a need for an efficient method to analyze not only residential location choice but also energy consumption behaviors.

Increasing attention has been focused on analyzing the choice of household location in certain zones and estimating energy consumption [26, 27, 28, 29, 30]. Despite efforts have been made to analyze the energy consumption in housing sector, few researchers have addressed the effect of housing location choice behavior on household energy consumption from a microeconomic viewpoint. Raising awareness of these concepts academic studies at the micro level is crucial for 
providing advice to successful policy making to encourage compact development and reduction of energy consumption of the city.

This paper aims to investigate households' reactions to compact development policy by simulating housing location choice and consumption behaviors of residents. A scheme is introduced to forecast household energy use based on consumption behaviors. Using a modelling approach, the paper simulates the influence of three types of relocation policies on residential location choice and consumption behaviors. Subsidy policy is introduced as a positive strategy for giving subsidy to households who relocate in certain zones. Taxation policy is introduced as a negative strategy for households who live outside of designed zones. Additionally, a joint policy that combines subsidy and taxation is also analyzed. A comparative analysis is conducted for comparing the energy results of three types of policy scenarios to give suggestions for energy saving towards compact development in Kumamoto.

\section{Methods and data sources}

Facing environmental problems, the Kumamoto municipal government plans for compact development. Decreasing and ageing population and urban sprawl are main challenges. Kumamoto city will lose more than ten thousand people every five years after 2020 . The ratio of elders (older than 65) will increase from $18.7 \%$ in 2005 to $29.7 \%$ in 2030. Meanwhile, Kumamoto is experiencing a process of urban sprawl. Considering the above challenges, Kumamoto city tries to promote compact development through relocation subsidy policies, which aim to attracting citizens moving from suburban area to the central urban area. This type of policy has been implemented in Japanese cities such as Toyama, Gifu, Kanazawa, and Takayama. A maximum of 10,000 yen of rent subsidy will be given to households who move to the designated zones for three years in Toyama, compared to a maximum of 20,000 yen per month in Gifu. In Kanazawa and Takaoka, households who buy houses located in the designated zones will receive a grant subsidy of up to 2,000,000 yen and 1,000,000 yen, respectively. As in other cities in Japan, the Kumamoto local government would like to be involved in residential housing to internalize the external effect of compact city policies.

To investigate the effect of relocation subsidy policies on residential location choice behaviors and consumption behaviors in Kumamoto, three key points must be addressed in this study: 1) the influence on residential location choice; 2) the influence on consumption behaviors; and 3) the influence on energy consumption. Based on these points, the content in this section is organized as five parts: 1) to introduce relocation policy scenarios in Kumamoto, 2) to build a residential relocation choice model, 3) to construct a model to estimate consumption behaviors and demand for goods, 4) to build a function for calculating energy consumption, and 5) to explain the data and data sources.

\subsection{Relocation Policy Scenarios in Kumamoto}

Three types of relocation policies are analyzed, naming relocation subsidy policy, suburban residence taxation policy, and relocation subsidy plus suburban residence taxation policy.

2.1.1Relocation subsidy policy 
Relocation subsidy policy is a type of policy that government provides subsidy to the household who relocate their home in the designated area. The subsidy is paid only for the households who relocate to the target zones from other zones. Two strategies are considered for household relocation. The first strategy is called P1-A, in which the households are encouraged to move into zones located around transit centers or living centers with dense populations and high public service accessibility. The second strategy is called P1-B, in which the households are supposed to relocate to a circle with a radius of $4 \mathrm{~km}$ from the city center. Two subsidy levels are set at 10,000 yen / month (333 yen / day) and 5,000 yen / month (166 yen / day). Based on the relocation place strategies and subsidy amounts, four scenarios are established: P1-A-10000, P1A-5000, P1-B-10000, and P1-B-5000. In scenario of P1-A-10000, one household receive 10,000 yen per month as the subsidy if they move into zones indicated in P1-A. The policy of P1-A5000 indicates that one household receives subsidy of 5000 yen / month when they relocate to the zones in the P1-A case. P1-B-10000 suggests that 10000 yen is given to a household each month if they relocate to a home in designated zones of P1-B. In the case of P1-B-5000, 5000 yen is provided if one household relocates the home to the zones for P1-B.

\subsubsection{Suburban residence taxation policy}

This type of policy influences the location decision in a negative way. Tax is collected from households who live in the withdrawal area, which is designated by the government. Suggested by the tax policy in the existing literature by Ujihara et al. [31], 10\% of the land rent is taxed as an extra cost of staying.

\subsubsection{Relocation subsidy plus suburban residence taxation policy}

This policy considers both a positive relocation subsidy and the negative taxation of suburban residence. Four types of polices are included. The combination of policy P1-A-10000 and suburban residence taxation policy is called P3-A-10000, while the combination of P1-A-5000 and the suburban residence taxation policy is called P3-A-5000. P3-B-10000 indicates the P1-B10000 policy combined with the suburban residence taxation policy. P3-B-5000 indicates the P1B-5000 policy combined with the suburban residence taxation policy.

\subsection{Residential Relocation Choice Model}

Households are assumed to make their home relocation decisions based on the utility level in different zones. A logit model is used to forecast the possibility of home relocation based on the utility (Eq. (1)).

$h_{j i}^{*}=h_{j} \cdot \frac{\exp \left(u_{i}+\pi_{i}\right)}{\sum_{k} \exp \left(u_{k}+\pi_{k}\right)}$

$h^{*}{ }_{j i}$ indicates the number of households which move from zone $j$ to zone $i . h_{j}$ is the number of households in zone $j . u_{i}$ is the individual utility level in zone $i$, which is determined by the consumption of goods. $\pi_{i}$ is an index variable that reflect the accessibility of the zone. It is determined by the number of clinics per unit area (number $/ \mathrm{km}^{2}$ ), number of shops (number / $\mathrm{km}^{2}$ ), number of supermarkets (number $/ \mathrm{km}^{2}$ ), and central commercial district dummy value (take 1 if the zone is within central commercial district, otherwise take 0 ). The relocation cost of moving from zone $i$ to zone $j$ is assumed to be the same regardless of the distance between zones. 


\subsection{Model to Estimate Consumption Behaviors and Demand for Goods}

\subsubsection{Assumptions}

The model used in this study is supposed be a " closed-city " model, which is characterized by a fixed population of urban residents who maximize the utility by consuming goods subject to a budget constraint. There is no import and export with outside world. Utility is closely related to consumption behaviors, which is a representation of preferences for goods and services. People are assumed to make consumption decisions based on their preferences for different goods, the cost of goods, and their budget constraints (income) to maximize the utility. The following assumptions are vital to developing the model to estimate consumption behaviors based on utility: 1) the "representative household" in each zone is assumed to consume two types of goods: composite goods and general goods. General goods are all goods except transport goods and land. 2) Composite goods include transport goods and land. The demand for composite goods is a function of demand of transport goods and land. 3) It is assumed that transport goods include not only commuter trips by car and public transport but also car and pedestrian trips for everyday life, such as shopping, going to hospitals, and recreation. 4) The demand for land is reflected by the living space of residential households. 5) Utility is a function of the demand for composite goods and general goods. 6) The "representative household" spends all of its income on the consumption of goods. No saving is assumed. 7) The demand for goods in reality equals the demand for goods at maximum utility.

\subsubsection{Constant Elasticity of Substitution functions based on consumption behaviors}

A four-stage CES (Constant Elasticity of Substitution) function is used to express utility. The nested structure is shown in Fig. 1. Five CES functions are developed to reflect the relationship between goods at four stages (Eq. (2)-Eq. (6)). At the first stage, the household utility level at zone $i$ indicated as $u_{i}$ is determined by the consumption of composite goods and general goods (Eq. (2)). All variables in this paragraph explain the household demand per day in zone $i$. The demand of composite goods and general goods are express by variables of $x_{A i}$ and $x_{G i}$, respectively. At the second stage, composite goods include land and transport goods (Eq. (3)). $x_{L i}$ is the demand of land and $x_{T i}$ is the demand of transport goods. At third stage, transport goods are classified as everyday life trips and commuter trips according to the purpose of the trips (Eq. (4)). Everyday life trips include car trips and pedestrian trips for shopping and recreation. Commuter trips are trips for working, schooling, returning home, and business. The demand of everyday life trips and commuter trips are indicated by variables of $x_{P i}$ and $x_{O i}$, respectively. At the fourth stage, different traffic mode share is shown. Eq. (5) shows the share relationship between the demand of car trips $\left(x_{C l i}\right)$ and walking trips $\left(x_{W i}\right)$ for everyday life trips. Eq. (6) shows the share relationship between the demand of car trips $\left(x_{C 2 i}\right)$ and public transport trips $\left(x_{M i}\right)$ for commuter trips.

$$
\begin{aligned}
& u_{i}\left(x_{G i}, x_{a i}\right)=\left\{\alpha_{G} x_{G i}{ }^{\left(\sigma_{1}-1\right) / \sigma_{1}}+\alpha_{A} x_{A i}{ }^{\left(\sigma_{1}-1\right) / \sigma_{1}}\right\} \sigma^{\sigma_{1} /\left(\sigma_{1}-1\right)} \\
& x_{A i}\left(x_{L i}, x_{T i}\right)=\left\{\alpha_{L} x_{L i}{ }^{\left(\sigma_{2}-1\right) / \sigma_{2}}+\alpha_{T} x_{T i}{ }^{\left(\sigma_{2}-1\right) / \sigma_{2}}\right\}^{\sigma_{2} /\left(\sigma_{2}-1\right)} \\
& x_{T i}\left(x_{P i}, x_{O i}\right)=\left\{\alpha_{P} x_{P i}^{\left(\sigma_{3}-1\right) / \sigma_{3}}+\alpha_{O} x_{O i}^{\left(\sigma_{3}-1\right) / \sigma_{3}}\right\} \sigma_{3} /\left(\sigma_{3}-1\right) \\
& x_{P i}\left(x_{C 1 i}, x_{W i}\right)=\left\{\alpha_{C 1} x_{C 1 i}^{\left(\sigma_{4}-1\right) / \sigma_{4 p}}+\alpha_{W} x_{W i}^{\left(\sigma_{4 p}-1\right) / \sigma_{4 p}}\right\}^{\sigma_{4 p} /\left(\sigma_{4 p}-1\right)}
\end{aligned}
$$




$$
x_{O i}\left(x_{C 2 i}, x_{M i}\right)=\left\{\alpha_{C 2} x_{C 2 i}^{\left(\sigma_{40}-1\right) / \sigma_{40}}+\alpha_{M} x_{M i}^{\left(\sigma_{40}-1\right) / \sigma_{40}}\right\}^{\sigma_{40} /\left(\sigma_{40}-1\right)}
$$

$\sigma_{1}, \sigma_{2}, \sigma_{3}, \sigma_{4 \mathrm{P}}$, and $\sigma_{4 \mathrm{O}}$ are the elasticity of substitution between two types of goods at the first, second, third, and fourth stages, respectively. $\alpha_{G}$ and $\alpha_{A}$ are the share parameters, indicating the composite goods and general goods expenditures as a share of total income. $\alpha_{L}$ and $\alpha_{T}$ are the expenditure share of land and transport goods to the total expenditure of composite goods respectively. $\alpha_{P}$ and $\alpha_{O}$ are the expenditures share of everyday trips and commuter trips to the total expenditure of transport goods. $\alpha_{C 1}$ and $\alpha_{W}$ are the expenditure share of car trips and walking trips to the expenditure of everyday trips. $\alpha_{C 2}$ and $\alpha_{M}$ are the parameters that explain the expenditure share of car trips and public transport trips to the total expenditure of commuter trips.

\subsubsection{Demand for goods}

Five maximization problems should be solved at four stages to fix the demand of goods at maximum utility. At the fourth stage, the demand of everyday trips and commuter trips is determined by solving two maximization problems (Eq. (7) and Eq. (8)) under the constraint of transport budgets for commuter and everyday trips. At the third stage, the demand of total trips is determined by the solutions to the maximization problem of Eq. (9) under the transport goods budget constraint. At the second stage, the demand of composite goods is determined by the optimal solutions to the maximization problem (Eq. (10)) for transport goods and land under the composite goods budget constraint. At the first stage, the utility is determined by the optimal solutions of the maximization problem as Eq. (11) for composite goods and general goods under the income constraint. The detailed information for solving five maximization problems is shown in the Appendix.

$$
\begin{aligned}
\max _{\left\{x_{C 2 i}, x_{M i}\right\}} & x_{O i}=\left\{\alpha_{C 2} x_{C 2 i}{ }^{\left(\sigma_{40}-1\right) / \sigma_{40}}+\alpha_{M} x_{M i}{ }^{\left(\sigma_{40}-1\right) / \sigma_{40}}\right\}^{\sigma_{40} /\left(\sigma_{40}-1\right)} \\
\text { s.t. } & p_{C 2 i} x_{C 2 i}+p_{M i} x_{M i} \leq I_{4 O i} \\
\max _{\left\{x_{C 1 i}, x_{W i}\right\}} & x_{P i}=\left\{\alpha_{C 1} x_{C 1 i}{ }^{\left(\sigma_{4 P}-1\right) / \sigma_{4 P}}+\alpha_{W} x_{W i}{ }^{\left(\sigma_{4 P}-1\right) / \sigma_{4 P}}\right\}^{\sigma_{4 P} /\left(\sigma_{4 P}-1\right)} \\
\text { s.t. } & p_{C 1 i} x_{C 1 i}+p_{W i} x_{W i} \leq I_{4 P i} \\
\max _{\left\{x_{P i}, x_{O i}\right\}} & x_{T i}=\left\{\alpha_{P} x_{P i}{ }^{\left(\sigma_{3}-1\right) / \sigma_{3}}+\alpha_{O} x_{O i}{ }^{\left(\sigma_{3}-1\right) / \sigma_{3}}\right\}^{\sigma_{3} /\left(\sigma_{3}-1\right)} \\
\text { s.t. } & p_{P i} x_{P i}+p_{O i} x_{O i} \leq I_{3 i} \\
\max _{\left\{x_{L i}, x_{T i}\right\}} & x_{A i}=\left\{\alpha_{L} x_{L i}{ }^{\left(\sigma_{2}-1\right) / \sigma_{2}}+\alpha_{T} x_{T i}{ }^{\left(\sigma_{2}-1\right) / \sigma_{2}}\right\} \sigma_{2} /\left(\sigma_{2}-1\right) \\
\text { s.t. } & p_{L i} x_{L i}+p_{T i} x_{T i} \leq I_{2 i} \\
\max _{\left\{x_{G i}, x_{A i}\right\}} & u_{i}=\left\{\alpha_{G} x_{G i}{ }^{\left(\sigma_{1}-1\right) / \sigma_{1}}+\alpha_{A} x_{A i}{ }^{\left(\sigma_{1}-1\right) / \sigma_{1}}\right\} \\
\text { s.t. } & p_{G i} x_{G i}+p_{A i} x_{A i} \leq I_{i} /\left(\sigma_{1}-1\right)
\end{aligned}
$$


$p_{C l i}$ and $p_{W i}$ are the prices of car trip and walking trips for everyday life, respectively. $p_{C 2 i}$ and $p_{M i}$ are the prices of commuter trips by car and public transport (yen/trip), respectively. $p_{P i}$ and $p_{O i}$ are the prices of everyday life and commuter trips, respectively. $p_{T i}$ and $p_{L i}$ are the prices of transport goods and land, respectively. $p_{G i}$ and $p_{A i}$ are the prices of general goods and composite goods, respectively. $I_{4 P i}$ and $I_{4 O i}$ are the traffic budget for everyday life trips and commuter trips (yen/ household• day). $I_{3 i}$ is the transport goods budget (yen/ household $\cdot$ day). $I_{2 i}$ is the budget of composite goods (yen/ household • day). $I_{i}$ is income (yen/ household • day).

By integrating the solutions of five maximization problems, the optimal demands of general goods $\left(x_{G i}^{*}\right)$, demand of land $\left(x_{L i}^{*}\right)$, and demand of car trips, public transport trips, and walking trips $\left(x_{m i}^{*}\right)$ at maximum utility are shown as Eq. (12), Eq. (13), and Eq. (14).

$$
\begin{aligned}
& x_{G i}^{*}=\left(\frac{\alpha_{G}}{p_{G i}}\right)^{\sigma_{1}} \frac{I_{i}}{\alpha_{G}^{\sigma_{1}} p_{G i}^{1-\sigma_{1}}+\alpha_{A}^{\sigma_{1}} p_{A i}^{1-\sigma_{1}}} \\
& x_{L i}^{*}=\left(\frac{\alpha_{L}}{p_{L i}}\right)^{\sigma_{2}} \frac{I_{i}}{\alpha_{L}^{\sigma_{2}} p_{L i}^{1-\sigma_{2}}+\alpha_{T}^{\sigma_{2}} p_{T i}^{1-\sigma_{2}}}\left(1-\frac{p_{G i}}{\alpha_{G}^{\sigma_{1}} p_{G i}^{1-\sigma_{1}}+\alpha_{A}^{\sigma_{1}} p_{A i}^{1-\sigma_{1}}}\right)
\end{aligned}
$$

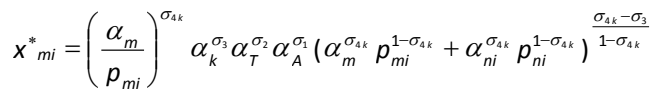

$$
\begin{aligned}
& \left\{\begin{array}{l}
\alpha_{p}^{\sigma_{3}}\left(\alpha_{W}^{\sigma_{4 p}} p_{W i}^{1-\sigma_{4 \rho}}+\alpha_{c 1}^{\sigma_{4 p}} p_{C i}^{1-\sigma_{4 p}}\right)^{1-\sigma_{3}} \\
+\alpha_{o}^{\sigma_{3}}\left(\alpha_{M}^{\sigma_{40}} p_{M i}^{1-\sigma_{40}}+\alpha_{c 2}^{\sigma_{40}} p_{C 2 i}^{1-\sigma_{40}}\right)^{-\sigma_{3}}
\end{array}\right\}^{\frac{\sigma_{3}-\sigma_{2}}{1-\sigma_{3}}}
\end{aligned}
$$

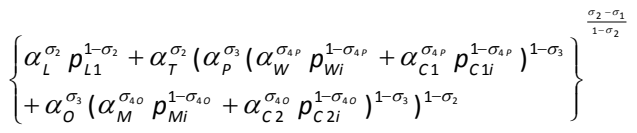

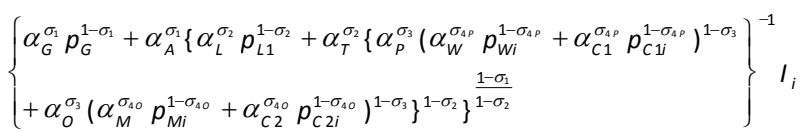

\subsection{Energy Estimation Function}

Energy consumption is estimated based on the demand for goods. As shown in Eq. (15), E is the total energy consumption of the region, which is a function of $E_{i}$. $E_{i}$ is defined as the energy consumption of one household per day in zone $i . P_{i}$ denotes the number of households in zone $i$. $e_{G}, e_{L}, e_{C}, e_{W}$, and $e_{M}$ are the energy units of general goods, land, car trips, walking trips, and public transport trips, respectively. Energy units are used to evaluate the energy needed to consume one unit of goods. $t_{C i}, t_{W i}$, and $t_{M i}$ are the trip times for car trips, walking trips, and public transport trips, respectively. Trip time variables are introduced into the estimation function to reflect the relationship between energy consumption and traffic congestion. $x_{G i}, x_{L i}$, $x_{C i}, x_{W i}$, and $x_{M i}$ indicate the demand for general goods, land, car trips, walking trips, and public transport trips, respectively. 


$$
E=\sum_{i} E_{i} \cdot P_{i}=\sum_{i}\left(e_{G} x_{G i}+e_{L} x_{L i}+e_{C} t_{C i} x_{C 1 i}+e_{W} t_{W i} x_{W i}+e_{C} t_{C i} x_{C 2 i}+e_{M} t_{M i} x_{M i}\right) \cdot P_{i}
$$

\subsection{Data and Data Sources}

\subsubsection{Primary number of trips $\left(x_{C 1 i}, x_{W i}, x_{C 2 i}, x_{M i}\right)$}

The primary number of trips for different purposes in zone $i$ is obtained from the Personal Trip Survey (PTS) in 2010. The PTS is a person-based travel survey conducted every ten years by the Ministry of Land, Infrastructure and Transport (MLIT) in Kumamoto. The data are aggregated by traffic zone. The number of trips by car, foot, and public transport for commuting and everyday purposes is calculated as the total number of trips divided by the number of households.

\subsubsection{Trip time of car trips, walking trips, and public transport trips $\left(t_{C i}, t_{W i}, t_{M i}\right)$}

Trip time of car and public transport trips is determined by the assignment result of car trips and mass transit trips on the Kumamoto transport network. Trip time in zone $i$ is the average time for all trips from zone $i$ to other zones. Trip time of walking trips is calculated by dividing the distance between zones by the walking speed $(5 \mathrm{~km} / \mathrm{hour})$. Trip time of walking trips is the average time of all trips from zone $i$ to other zones.

\subsubsection{Price of goods}

The price of general goods, $p_{G i}$, is set to one as a numeraire unit. The price of composite goods, $p_{A i}$, is determined by the price of transport goods and land according to CES functions. The price of transport goods is influenced by the prices of car trips, walking trips, and public transport trips. We used the same method to estimate the price of a car trip in both cases of everyday life trips and commuter trips. The price of a car trip is determined by following equation: $p_{C l i}=[$ (running fee unit $(\mathrm{yen} / \mathrm{km} \cdot$ vehicle $) \times$ minimum distance from zone $\mathrm{i}$ to $\mathrm{j}(\mathrm{km} /$ trip $))] /$ average number of passengers $($ trip/vehicle $), p_{C 2 i}=\left[\right.$ (running fee unit $\left(\mathrm{yen} / \mathrm{km}^{*}\right.$ vehicle $) \times$ minimum distance from zone $\mathrm{i}$ to $\mathrm{j}(\mathrm{km} /$ trip))]/ average number of passengers (trip/vehicle). The running fee unit is available from the data from MLIT, which measures the monetary running cost per vehiclekilometer, including fees related to oil, tires, tubes, vehicle maintenance and vehicle depreciation. The number of passengers in a car is 1.21 according to MLIT. The price of a mass transit trip is determined by the public transport fare resulting from trip assignment. The price of walking trips is set at 1 yen/trip.

\subsubsection{The demand of land and price of land}

The primary demand of land for each household per day is estimated by dividing the total area of residential land by the number of households in each zone. The land price of the zone is obtained by dividing the aggregated land price of the district by the price ratio of land along main roads in zones. The daily land price $p_{L i}$ (yen $/ \mathrm{m}^{2}$.day) is the result of dividing the land price of the zone by 12775 ( 35 years). It is assumed that households need to pay a mortgage for the land for 35 years.

\subsubsection{Income $I_{i}$}

It is difficult to obtain income data on households in each zone. Because a positive relationship between land price and income is assumed [32, 33, 34], the zone's income ratio is assumed to be equal to the zonal land price ratio of the main roads. We distribute the total 
income for each administrative district among zones according to the land price ratio of the main roads in 2010. The land price data are available from the Japanese National Tax Agency.

\subsubsection{Energy consumption units}

The energy consumption unit of general goods, $e_{G}(\mathrm{kcal} / \mathrm{yen})$, is calculated by dividing the energy use in the residential sector by the general goods expenditure of one household. Except the expenditure of transport goods and land, the remaining income is assumed be spent on general goods. The energy consumption of land is assumed to be equal to the energy required for constructing new houses in the zone. The energy consumption unit of land, $e_{L}\left(\mathrm{kcal} / \mathrm{m}^{2}\right)$, is determined by the demand for new houses and the operational life of houses. Therefore, $e_{L}$ $\left(\mathrm{kcal} / \mathrm{m}^{2}\right)$ is estimated by the total energy required for the construction of new houses and 35 years (12775 days).

The energy consumption units of car and public transport trips are determined by the running fee unit and trip speed. The running fee unit (yen/km·vehicle) is obtained from MLIT. Energy units for car and public transport trips are estimated as follows: $e_{C}\left(\right.$ or $\left.e_{M}\right)=$ energy unit of trip distance $(\mathrm{kcal} /$ trip $\cdot \mathrm{min}) \times$ average speed $(\mathrm{km} / \mathrm{min})$. According to the study by Matsuo [35], the energy consumption unit for walking trips, $e_{W}(\mathrm{kcal} / \mathrm{trip} . \mathrm{min})$, is set at $0.0556 \mathrm{kcal}$ per trip per minute. All results for the estimated energy consumption units of goods are shown in Table 1.

Table 1 Energy consumption units of goods

\begin{tabular}{ll}
\hline Goods & Energy consumption unit \\
\hline General goods $e_{G}(\mathrm{kcal} / \mathrm{yen})$ & 3.044 \\
\hline Land $e_{L}\left(\mathrm{kcal} / \mathrm{m}^{2}\right)$ & 10.22 \\
\hline Car trip $e_{C}(\mathrm{kcal} / \mathrm{trip} . \mathrm{min})$ & 137.653 \\
\hline Public transport trip $e_{M}(\mathrm{kcal} / \mathrm{trip} . \mathrm{min})$ & 14.498 \\
\hline Walking trip $e_{W}(\mathrm{kcal} /$ trip.min $)$ & 0.0556 \\
\hline
\end{tabular}

\section{Results}

\subsection{Parameter Estimation}

\subsubsection{Parameters in the residential relocation choice model}

The parameters in the residential relocation choice model were estimated based on 2010 PTS data for 177 zones in Kumamoto. The data were aggregated by traffic zone. Except the number of shops, all variables show significant influence on the residential relocation choice (Table 2). The possibility of relocating increases as the utility level and accessibility of services improve.

Table 2 Estimation results of parameters in the residential relocation choice model

\begin{tabular}{lll}
\hline & Estimate & $\mathrm{t}$ value \\
\hline Constant & 3.19 & 8.61 \\
\hline Utility & $1.75 \times 10^{-4}$ & 3.32 \\
\hline
\end{tabular}




\begin{tabular}{lll}
\hline Number of clinics & $5.61 \times 10^{-2}$ & 4.13 \\
\hline Number of shops & $2.70 \times 10^{-3}$ & 0.622 \\
\hline Number of supermarkets & 0.0871 & 1.32 \\
\hline $\begin{array}{l}\text { Central commercial district } \\
\text { (dummy) }\end{array}$ & -5.57 & -7.23 \\
\hline Correlation coefficient R & 0.60 & \\
\hline
\end{tabular}

\subsubsection{Parameters in the utility function}

As shown in Table 3, the substitution elasticity between composite goods and general goods, $\sigma_{1}$, is less than one. The value of $\sigma_{2}$ indicates a relatively weak substitution relationship between land and transport. The substitution elasticity between car trips and public transport trips and between car trips and walking trips is larger than the substitution elasticity between commuter trips and everyday life trips. The price strongly influences the traffic mode choice, as suggested by the larger substitution elasticity values of $\sigma_{4 P}$ and $\sigma_{4 O}$.

The share parameter of $\alpha$ indicates the expenditure of goods to the budget. The value of expenditure share parameter $\alpha_{G}$ is 0.925 , indicating that households spend most of their income on general goods. Only a small portion of income is used for composite goods, as shown by the value of 0.075 for $\alpha_{A}$. Around eighty percent of the budget for composite goods is used for land, with a value of 0.793 for $\alpha_{L}$. Comparably, twenty percent of the budget is spent on transport goods, suggested by the value of $\alpha_{T}$ as 0.207 . The estimation result of $\alpha_{O}$ suggests that more than eighty percent of the transport budget is used for commuter trips, compared to eighteen percent for everyday life trips. The value of $\alpha_{C l}$ is 0.992 , indicating that most of the trip expenditure for everyday trips is for car trips. However, the share of car trips decreases to 0.426 for commuter trips. The expenditure for walking trips is as small as 0.008 because of less costly and small mode share. For commuter trips, the share of car trips decreases to 0.426 . More than fifty percent of the budget is spent on public transport trips, shown as the value of $\alpha_{M}$ as 0.574 .

Table 3 Estimation results of parameters in the utility function

\begin{tabular}{llllllll}
\hline$\sigma_{1}$ & $\sigma_{2}$ & $\sigma_{3}$ & $\sigma_{4 P}$ & $\sigma_{4 O}$ & $\alpha_{G}$ & $\alpha_{A}$ & $\alpha_{L}$ \\
\hline 0.903 & 0.942 & 0.828 & 1.930 & 2.150 & 0.925 & 0.075 & 0.793 \\
\hline$\alpha_{T}$ & $\alpha_{P}$ & $\alpha_{O}$ & $\alpha_{G}$ & $\alpha_{W}$ & $\alpha_{C 2}$ & $\alpha_{M}$ & \\
\hline 0.207 & 0.182 & 0.818 & 0.992 & 0.008 & 0.426 & 0.574 & \\
\hline
\end{tabular}

\subsection{Residential Relocation Choice and Population Distribution}

The change rates of population in P1-A-10000 and P1-A-5000 scenarios are shown in Fig. 2.a and Fig. 2.b. $1.8 \%$ of residents move to designated zones in the P1-A-10000 policy scenario, compared to $1.01 \%$ in P1-A-5000. As shown by Fig. 3.a and Fig. 3.b, more than 1.61 percent of households move into the central urban area in P1-B-10000 policy scenario. Meanwhile, $1 \%$ of households would like to relocate to the central urban area under P1-B-5000 policy scenario. The population distribution result of P2 suggests a wide spread, but not expected strong effect on housing relocation choice (Fig. 4). The number of households is estimated to increase by 0.1 
percent in the designated area in the scenario of $\mathrm{P} 2$. P3, which integrates the relocation subsidy policy and suburban residence taxation policy, is much more effective on attracting households to a certain area, with increment rate of 2.2 and 1.1 percent for subsidies of 10000 and 5000 , respectively. Fig. 5.a and Fig. 5.b illustrate the population change rate in P3-A-10000 and P3-A5000. Compared to the result of P3-B-10000, P3-A-5000 shows a limited effect on the rate of population change (Fig. 6.a and Fig. 6.b).

\subsection{Demand for goods}

Table 4 presents the estimated demand of goods. The demand for goods in each policy scenario is compared to the data of the base year in 2010 by a demand ratio. It is the rate between demand of goods in scenarios and the demand in the base year. As shown in Table 4, averaged 6,937 units of general goods are consumed by one household in one day. Except the policy scenario of P2, a slight increasing trend is found for the demand of general goods in the P1-A, P1-B, P3-B, and P3-A scenarios. Although the demand of land increases in P1-A and P1-B scenarios, decreased values are shown in the results of $\mathrm{P} 2, \mathrm{P} 3-\mathrm{B}$, and $\mathrm{P} 3-\mathrm{A}$. The scenarios also show different effects on demand of trips. Both P3-A and P3-B show effects on decreasing the number of trips for commuting and everyday life. However, public transport and walking trips increase in these two kinds of policy scenarios.

Table 4 Estimated demand for goods and trip time

\begin{tabular}{|c|c|c|c|c|c|c|c|c|c|c|}
\hline & $\begin{array}{l}\text { Base } \\
\text { year }\end{array}$ & $\begin{array}{l}\text { P1-A- } \\
10000 \\
\text { ratio }\end{array}$ & $\begin{array}{l}\text { P1-A- } \\
5000 \\
\text { ratio }\end{array}$ & $\begin{array}{l}\text { P1-B- } \\
10000 \\
\text { ratio }\end{array}$ & $\begin{array}{l}\text { P1-B- } \\
5000 \\
\text { ratio }\end{array}$ & $\begin{array}{l}\mathrm{P} 2 \\
\text { ratio }\end{array}$ & $\begin{array}{l}\mathrm{P} 3-\mathrm{A}- \\
10000 \\
\text { ratio }\end{array}$ & $\begin{array}{l}\mathrm{P} 3-\mathrm{A}- \\
5,000 \\
\text { ratio }\end{array}$ & $\begin{array}{l}\text { P3-B- } \\
10000 \\
\text { ratio }\end{array}$ & $\begin{array}{l}\text { P3-B- } \\
5000 \\
\text { ratio }\end{array}$ \\
\hline $\begin{array}{l}\text { Total expenditure } \\
(\text { yen/day } \cdot \text { household) }\end{array}$ & 8,178 & 1.010 & 1.005 & 1.013 & 1.006 & 0.997 & 1.010 & 1.005 & 1.013 & 1.006 \\
\hline $\begin{array}{l}\text { Traffic expenditure } \\
(\text { yen/day } \cdot \text { household) }\end{array}$ & 187.1 & 1.005 & 0.993 & 1.011 & 1.004 & 1.000 & 1.002 & 0.988 & 1.000 & 1.006 \\
\hline $\begin{array}{l}\text { General goods (yen/day } \\
\cdot \text { household) }\end{array}$ & 6937 & 1.010 & 1.005 & 1.013 & 1.006 & 0.999 & 1.010 & 1.005 & 1.013 & 1.006 \\
\hline $\begin{array}{l}\text { Land }\left(\mathrm{m}^{2} / \text { day }\right. \\
\text { household) }\end{array}$ & 0.628 & 1.007 & 1.004 & 1.003 & 1.001 & 0.975 & 0.983 & 0.979 & 0.979 & 0.977 \\
\hline $\begin{array}{l}\text { Car trips for everyday } \\
\text { life } \\
\text { (trip/day } \cdot \text { household) }\end{array}$ & 0.341 & 1.003 & 0.996 & 1.008 & 1.002 & 1.000 & 0.998 & 0.986 & 0.994 & 1.004 \\
\hline $\begin{array}{l}\text { Car trips for } \\
\text { commuting } \\
(\text { trip/day } \cdot \text { household) }\end{array}$ & 0.895 & 1.001 & 0.994 & 1.006 & 1.001 & 0.999 & 0.994 & 0.979 & 0.988 & 1.002 \\
\hline $\begin{array}{l}\text { Walking trips } \\
(\text { trip/day } \cdot \text { household) }\end{array}$ & 0.395 & 1.012 & 1.007 & 1.017 & 1.009 & 1.003 & 1.016 & 1.012 & 1.023 & 1.012 \\
\hline $\begin{array}{l}\text { Public transport trips } \\
(\text { trip/day } \cdot \text { household) }\end{array}$ & 0.120 & 1.017 & 1.012 & 1.026 & 1.013 & 1.003 & 1.024 & 1.022 & 1.038 & 1.017 \\
\hline
\end{tabular}

\subsection{Energy consumption}

The estimated results of energy consumption are shown in Table 5. A ratio is also used to compare the energy consumption of scenarios to the energy demand in the base year of 2010 . 
One household requires 32,800 kcal of energy for one day. Increased energy consumption is shown in the results of P1-A-10000, P1-A-5000, P1-B-10000, P1-B-5000, P3-A-10000, and P3B-5000. However, P2 shows decreased energy consumption compared to the data of the base year. This means that taxation policy is helpful in reducing energy consumption. An average of $25,240 \mathrm{kcal}$ of energy is estimated for general goods in the base year. There is a slight increasing trend in the energy consumption for general goods in all scenarios. The energy for land is estimated to increase in P1-A-10000, P1-A-5000, P1-B-10000, and P1-B-5000 scenarios. Conversely, the results of P2, P3-A-10000, P3-A-5000, P3-B-10000, and P3-B-5000 show decreasing energy for land. Most of the energy for car trips is for commuter trips. $3,755 \mathrm{kcal}$ of energy is used for commuter trips, compared to 1,442 kcal for everyday trips. The policies of P1A-10000, P1-B-10000, and P1-B-5000 show effect on increasing the energy consumption by car trips. However, the results of P1-A-5000, P2, P3-A, and P3-B suggest a decreasing trend in energy use for car trips. All scenarios indicate increased energy for walking trips and public transport trips. Except for P1-A-5000, an increasing trend of energy consumption for all types of mode trips is shown in P1-A, P1-B, and P2. All scenarios show a positive effect on the travel time for car trips, walking trips, and public transport trips. Except P1-B-10000 and P1-B-5000, trip time decreases in the results of all scenarios.

Table 5 Estimated energy consumption

\begin{tabular}{|c|c|c|c|c|c|c|c|c|c|c|}
\hline & $\begin{array}{l}\text { Base } \\
\text { year }\end{array}$ & $\begin{array}{l}\text { P1-A- } \\
10000 \\
\text { ratio }\end{array}$ & $\begin{array}{l}\text { P1-A- } \\
5000 \\
\text { ratio }\end{array}$ & $\begin{array}{l}\text { P1-B- } \\
10000 \\
\text { ratio }\end{array}$ & $\begin{array}{l}\text { P1-B- } \\
5000 \\
\text { ratio }\end{array}$ & $\begin{array}{l}\mathrm{P} 2 \\
\text { ratio }\end{array}$ & $\begin{array}{l}\text { P3-A- } \\
10000 \\
\text { ratio }\end{array}$ & $\begin{array}{l}\mathrm{P} 3-\mathrm{A}- \\
5000 \\
\text { ratio }\end{array}$ & $\begin{array}{l}\text { P3-B- } \\
10000 \\
\text { ratio }\end{array}$ & $\begin{array}{l}\text { P3-B- } \\
5000 \\
\text { ratio }\end{array}$ \\
\hline $\begin{array}{l}\text { Total energy } \\
\text { consumption (kcal/day } \\
\text { · household) }\end{array}$ & 32,800 & 1.009 & 0.998 & 1.013 & 1.006 & 0.997 & 1.005 & 0.995 & 1.006 & 1.003 \\
\hline $\begin{array}{l}\text { Energy for general } \\
\text { goods }(\mathrm{kcal} / \text { day• } \\
\text { household) }\end{array}$ & 25,240 & 1.010 & 1.005 & 1.013 & 1.006 & 1.000 & 1.01 & 1.005 & 1.013 & 1.006 \\
\hline $\begin{array}{l}\text { Energy for land } \\
(\mathrm{kcal} / \mathrm{day} \cdot \text { household })\end{array}$ & 2,343 & 1.008 & 1.004 & 1.003 & 1.002 & 0.978 & 0.983 & 0.979 & 0.979 & 0.977 \\
\hline $\begin{array}{l}\text { Energy for car trips for } \\
\text { everyday life } \\
(\mathrm{kcal} / \text { day } \cdot \text { household })\end{array}$ & 1,442 & 1.006 & 0.963 & 1.021 & 1.005 & 0.992 & 0.993 & 0.959 & 0.992 & 1.002 \\
\hline $\begin{array}{l}\text { Energy for car trips for } \\
\text { commuter } \\
(\mathrm{kcal} / \text { day } \cdot \text { household })\end{array}$ & 3,775 & 1.005 & 0.961 & 1.02 & 1.004 & 0.992 & 0.989 & 0.953 & 0.986 & 1.001 \\
\hline $\begin{array}{l}\text { Energy for walking } \\
\text { trips } \\
(\mathrm{kcal} / \text { day } \cdot \text { household })\end{array}$ & 1.346 & 1.010 & 1.006 & 1.011 & 1.006 & 1.004 & 1.015 & 1.012 & 1.019 & 1.009 \\
\hline $\begin{array}{l}\text { Energy for public } \\
\text { transport trips } \\
(\mathrm{kcal} / \mathrm{day} \cdot \text { household })\end{array}$ & 160.7 & 1.016 & 1.011 & 1.022 & 1.012 & 1.004 & 1.024 & 1.024 & 1.036 & 1.015 \\
\hline $\begin{array}{l}\text { Time for car trips } \\
(\min / \text { day } \cdot \text { household })\end{array}$ & 31.09 & 0.996 & 0.973 & 1.011 & 1.002 & 0.993 & 0.995 & 0.978 & 0.994 & 0.994 \\
\hline $\begin{array}{l}\text { Time for walking trips } \\
(\mathrm{min} / \text { day } \cdot \text { household })\end{array}$ & 59.08 & 0.999 & 0.999 & 0.998 & 0.999 & 0.999 & 0.998 & 0.999 & 0.997 & 0.998 \\
\hline
\end{tabular}




\begin{tabular}{lllllllllll}
\hline $\begin{array}{l}\text { Time for public } \\
\text { transport (min/day } \\
\text { household) }\end{array}$ & 102.9 & 0.998 & 0.999 & 0.998 & 0.999 & 0.999 & 0.998 & 0.998 & 0.997 & 0.998 \\
\hline
\end{tabular}

\section{Discussion}

\subsection{Residential Relocation Choice}

Three types of policies show effects on residential relocation choice and population distribution. The subsidy policy influences the relocation choice in a positive way by providing subsidy to households who move to a designated area. The results show that the subsidy policy has a relatively strong effect on household relocation choices. Of course, different levels of subsidy show different expected effects on households' relocation choices. An average of one percent of the population moves into the area if the subsidy of 5000 yen per month is provided. While the subsidy policy of 10000 would increases two percent of residents who relocate to the designated area. However, tax policy in this study indicates very limited influence on the rate of population change. One reason may be the intensity of tax policy is not strong as subsidy policy. One household needs to pay 50 yen per day for living in zones which locate outside of the designed area. The amount of tax is much lower than the subsidy, which is 333 yen/day and 166 yen/day. The other reason could be the high income groups would like to sacrifice the tax and refuse to move into more compact living environment. Although the rate of population change under the integrated policy is higher than the rate in the subsidy policy, a lower possibility of relocation is shown in some zones under the integrated policy, such as urban zones far from the urban central area. Households in sub-center of the city have low willingness to relocate in the urban central area since the utility level and accessibility to service in sub-center is not low enough to make the relocation decision.

\subsection{Demand for Goods}

Households tend to increase their consumption of goods with the support of subsidy. Moreover, higher subsidy leads to more consumption. The relocation subsidy policy of P1 shows an increasing trend of the consumption of general goods, land, and trips. Of note is that the number of car trips decrease even with the subsidy of 5000. It indicates that residents would like to spend extra money on goods rather than on car trips. Households also adjust the traffic mode choice to maintain the mobility level and minimize the transport budget. The total traffic expenditure decreases because part of car trips is substituted by walking and public transport trips. The suburban residence taxation policy of P2 shows a negative effect on the expenditure because of lower income. There is no subsidy for households who relocate to the designated area. But there is tax for households who refuse to move. Thus the average income decreases relatively. Households need to reduce expenditures in case of less income. However, not all consumption of goods decreases. The consumption of general goods and car trips for everyday life remains stable even income decreases. Households who relocate to the dense city center area need less land for housing. Meanwhile, residents tend to walk more and use public transport as traffic mode rather than car for commuter trips. The influence of P3 on demand for goods is complex because of a combination of subsidy policy and tax policy. On one hand, the demand of general goods increases due to the subsidy. On the other hand, P3 shows an effect of reducing 
the demand for land due to the effect of the suburban residence taxation policy. P3 also has influence on the traffic mode share. The demand of car trips decreases. However, the demand for public transport and walking trips increases. The possibility of choosing walking and public transport as transport modes increases in a compact living environment as more households locate in the dense designated area.

\subsection{Energy Consumption}

Subsidy policy has a positive effect on energy consumption. With the support of the subsidy, households could spend more money on goods, contributing to more energy consumption. Although trip time of walking and public transport decreases in all subsidy policy scenarios of P1, the energy use of walking trips and public transport trips increase because of increased demand of such trips. Therefore, total energy consumption in P1 scenarios increased except P1A-5000. Although dense living environment is helpful for decreasing trip distance and reducing trip time, the effect on energy saving is offset by more consumption of general goods and land. Low level of subsidy encourages consumption of goods, but the effect on energy consumption is limited. Energy savings by shorter trip time outweigh the increased energy use for more consumption of goods. This may explain the lower total energy consumption of P1-A-5000. However, the outcome is different in the case of P1-B-5000 scenario, in which the population is supposed to be concentrated in a circle with a radius of $4 \mathrm{~km}$ from the city center. With more and more residents concentrated in the city center, more and severe traffic congestions are expected in such an urban structure. Trip time of car trips increases by $1.1 \%$ and $0.2 \%$ in P1-B-10000 and P1-B-5000, respectively.

Suburban residence taxation policy shows a relatively strong effect on energy reduction. This could be explained by the following reasons. First, the average income decreases due to the tax. Therefore, residents reduce the expenditure thus consumption of goods. Secondly, residents adjust the expenditure share of goods to maximize the utility, which is helpful to decrease energy consumption. The energy used for general goods remains stable. The consumption of energyintensive goods, such as land and car trips, decreases. Increased walking trips and public transport trips attribute to less energy consumption. Lastly, reduced trip time decreases the energy consumption. Some households would relocate their homes to a dense designated area, which encourages shorter trip distance and less trip time.

With a combination of relocation subsidy and suburban residence taxation policy, P3 shows a medium effect on energy consumption, neither as high as P1, nor low as P2. Except P3-A-5000, energy consumption increases in all scenarios of P3. On one hand, the relocation subsidy increases the consumption of goods. On the other hand, the suburban residence taxation policy means that households who refuse to move to a certain area have to sacrifice part of their consumption because of the tax. The two opposite influence directions lead to a medium increase in energy consumption. Of note is that the energy for land is reduced in all scenarios of P3. Households tend to choose a dense living environment, which leads to less land consumption at average. Moreover, traffic conditions are much more convenient because there are fewer trips. This leads to shorter trip times, resulting in less energy consumption for car trips.

\section{Conclusion}


To investigate the effect of housing relocation policy on energy consumption, this study simulated the consumption behaviors of households under scenarios of subsidy policy and taxation policy in Kumamoto. Residential relocation choice behavior and consumption behaviors were estimated through modeling. A function was also introduced to calculate the energy consumption based on estimated behaviors and demand of goods. The simulation results in the Kumamoto metropolitan region show four major findings. First, both subsidy policy and suburban residence taxation policy influence household consumption behaviors and energy consumption. Second, subsidy policies show effects on household relocation choice, attracting households to the designated area. However, more general goods and more energy consumption were found in most subsidy scenarios. Third, suburban residence taxation policy showed a relatively strong effect on energy reduction due to less consumption of car trips and land, and shorter trip time. But it shows a very limited effect on housing relocation choice. Finally, compared to subsidy policy alone, the integrated policy of subsidy and suburban residence taxation showed less effect on energy consumption. The incensement rate was lower.

The study provides deep insights into consumption behaviors and energy use of households at the zone scale, and included a holistic perspective on the impact of relocation policies. It extends the concept of compact development analysis to a very small aggregated level and then compares the effect of three types of housing relocation policies in Kumamoto. To the authors' knowledge, there are no other models that attempted to quantify consumption of goods and energy use for a household at the zone scale as this work. The methodology of this paper evaluates the effect of urban relocation polices on energy consumption through personal consumption behaviors from a new viewpoint. Unlike previous studies which have taken a limited view of housing relocation choice behaviors, this study focuses not only on housing relocation choice behaviors but also on consumption behaviors from a microeconomic viewpoint. Energy consumption is also estimated to give a clear idea of the environmental outcome of policies. The study provides a context for evaluating the impacts of housing relocation policies on relocation choice behaviors and consumption behaviors. And it also allows a more quantitative comparison of energy use across different relocation policy scenarios. Analysis results could not only give suggestions for urban planners in Kumamoto, but also expand the field of analysis tool of policy making for governments aiming for dense housing relocation.

Most planning policies in advanced countries aim to develop a more sustainable urban development pattern of compact cities. However, the reality of declining populations in the city center and an increasing share of household in lower-density locations outside the central areas of cities makes achieving compact development challenging. Despite the general trend towards urban sprawl, in recent times, many cities have made policies which aim to attract households back into the central area by subsidies or tax. Although this is a good starting point for compact development, questions that related to the environmental outcome and behavior implications of such policies still remain. Policymakers need to consider not just the attraction of high density policies but also the environmental impacts of the residential communities they choose. Our paper provided deeper understanding of consumption behaviors and energy use in the context of Kumamoto at a micro level, and give suggestions for the successful implementation of housing relocation policies toward compact development at Kumamoto.

Based on the findings of this study, there are three implications for the future policy making for compact development. First, residents would benefit from the subsidy policy through more goods and a better social life. However, the amount of subsidy should be carefully considered. 
Different subsidy levels show different effects on energy consumption. Change of consumption behaviors could save energy in a dense environment. But meanwhile the amount of consumption would increase due to the subsidy. The energy consumption of the whole city may increase because of more goods consumption. Moreover, the government should have a clear idea of the origin of subsidy and distribution of subsidy since they are important issues of the society. Second, it needs to think twice when make suburban residence taxation policy. Although it is found to be effective on reducing energy consumption, it is such a kind of punishment policy that could not be accepted easily by households. Finally, beyond money incentives such as a subsidy or tax, there is a significant role for urban planners to improve the design of the dwelling unit to provide residential environments that are suitable throughout all stages of an individual's life. This could increase the attractiveness of the dense living areas in the city center because it could improve the stability and quality of life experienced in these areas. All three points would benefit future academic study by deeply investigating on the relationship between consumption behaviors, energy use, and relocation choice behaviors. Useful findings could be driven form to give suggestions for urban planners, transport planner, and energy saving policy making that toward to compact development.

\section{Acknowledgments}

The project is sponsored by the Scientific Research Foundation for the Returned Overseas Chinese Scholars, State Education Ministry. The work described in this paper was also supported by the National Science Foundation of China (NSFC) (41301171). This work was supported by the K.C. Wong Magna Fund and the "Subsidy stimulation mechanism and the influence on the operation of bus companies" project (XK115D234), sponsored by the key discipline of "Transportation planning and management" of Ningbo city.

\section{Appendix A}

Four steps are included in the solution process. At first, the maximum problem of everyday life trips for car trips and public transport trips is shown as Eq. (A1), and the maximum problem of commuter trips for car trips and walking trips is shown as Eq. (A2):

$$
\begin{aligned}
\max _{\left\{x_{C 1 i}, x_{W i}\right\}} & x_{P i}=\left\{\alpha_{C 1} x_{C 1 i}{ }^{\left(\sigma_{4 P}-1\right) / \sigma_{4 P}}+\alpha_{W} x_{W i}{ }^{\left(\sigma_{4 P}-1\right) / \sigma_{4 P}}\right\}^{\sigma_{4 P} /\left(\sigma_{4 P}-1\right)} \\
\text { s.t. } & p_{C 1 i} x_{C 1 i}+p_{W i} x_{W i} \leq I_{4 P i} \\
\max _{\left\{x_{C 2 i}, x_{M i}\right\}} & x_{O i}=\left\{\alpha_{C 2} x_{C 2 i}{ }^{\left(\sigma_{40}-1\right) / \sigma_{40}}+\alpha_{M} x_{M i}{ }^{\left(\sigma_{40}-1\right) / \sigma_{40}}\right\}^{\sigma_{40} /\left(\sigma_{40}-1\right)} \\
\text { s.t. } & p_{C 2 i} x_{C 2 i}+p_{M i} x_{M i} \leq I_{4 O i}
\end{aligned}
$$

Using Lagrangian method, the solutions of Eq.(A1) and Eq.(A2) are shown as Eq.(A3) and Eq.(A4):

$$
x_{m i}=\left(\frac{\alpha_{m}}{p_{m i}}\right)^{\sigma_{4 P}} \frac{I_{4 P i}}{\alpha_{C 1}^{\sigma_{4 P}} p_{C 1 i}^{1-\sigma_{4 P}}+\alpha_{W}^{\sigma_{4 P}} p_{W i}^{1-\sigma_{4 P}}} \quad \quad(m=C 1, W)
$$




$$
x_{n i}=\left(\frac{\alpha_{n}}{p_{n i}}\right)^{\sigma_{40}} \frac{I_{4 O i}}{\alpha_{C 2}^{\sigma_{40}} p_{C 2 i}^{1-\sigma_{40}}+\alpha_{M}^{\sigma_{40}} p_{M i}^{1-\sigma_{40}}} \quad \quad(n=C 2, M)
$$

The maximum demand of everyday life trips $\left(\mathrm{x}_{\mathrm{Pi}}^{*}\right)$ and maximum demand of commuter trips $\left(\mathrm{x}^{*} \mathrm{Oi}\right)$ are shown as Eq. (A5) and Eq. (A6):

$$
\begin{aligned}
& x_{P i}^{*}=\left(\alpha_{C 1}^{\sigma_{4 P}} p_{C 1 i}^{1-\sigma_{4 P}}+\alpha_{W}^{\sigma_{4 P}} p_{W i}^{1-\sigma_{4 P}}\right)^{1 /\left(\sigma_{4 P}-1\right)} \cdot I_{4 P i} \\
& x_{O i}^{*}=\left(\alpha_{C 2}^{\sigma_{4 O}} p_{C 2 i}^{1-\sigma_{4 O}}+\alpha_{M}^{\sigma_{4 O}} p_{M i}^{1-\sigma_{4 O}}\right)^{1 /\left(\sigma_{4 O}-1\right)} \cdot I_{4 O i}
\end{aligned}
$$

Thus the price of everyday life trips $\left(p_{P i}\right)$ and the price commuter trips $\left(p_{O i}\right)$ are shown as Eq. (A7) and Eq. (A8):

$$
\begin{aligned}
& p_{P i}=\left(\alpha_{C 1}^{\sigma_{4 P}} p_{C 1 i}^{1-\sigma_{4 P}}+\alpha_{W}^{\sigma_{4 P}} p_{W i}^{1-\sigma_{4 P}}\right)^{1 /\left(1-\sigma_{4 P}\right)} \\
& p_{o i}=\left(\alpha_{C 2}^{\sigma_{4 O}} p_{C 2 i}^{1-\sigma_{4 O}}+\alpha_{M}^{\sigma_{4 O}} p_{M i}^{1-\sigma_{4 O}}\right)^{1 /\left(1-\sigma_{4 O}\right)}
\end{aligned}
$$

At the second stage, the maximum problem for the demand of transport goods is solved (Eq. (A9)).

$$
\begin{aligned}
\max _{\left\{x_{P i}, x_{O i}\right\}} & x_{T i}=\left\{\alpha_{P} x_{P i}{ }^{\left(\sigma_{3}-1\right) / \sigma_{3}}+\alpha_{O} x_{O i}{ }^{\left(\sigma_{3}-1\right) / \sigma_{3}}\right\}^{\sigma_{3} /\left(\sigma_{3}-1\right)} \\
\text { s.t. } & p_{P i} x_{P i}+p_{O i} x_{O i} \leq I_{3 i}
\end{aligned}
$$

The solution of Eq. (A9) is shown as Eq. (A10).

$$
x_{a i}^{*}=\left(\frac{\alpha_{a}}{p_{a i}}\right)^{\sigma_{3}} \frac{I_{3 i}}{\alpha_{P}^{\sigma_{3}} p_{P i}^{1-\sigma_{3}}+\alpha_{O}^{\sigma_{3}} p_{O i}^{1-\sigma_{3}}} \quad(a=O, P)
$$

The maximum demand of transport goods $\left(x_{T i}^{*}\right)$ is shown as Eq. (A11).

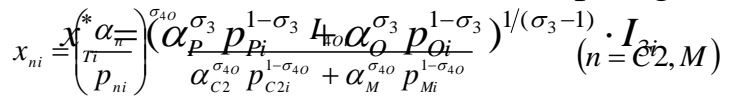

Thus the price of transport goods $\left(p_{T i}\right)$ is shown as Eq. (A12).

$$
p_{T i}=\left(\alpha_{P}^{\sigma_{3}} p_{P i}^{1-\sigma_{3}}+\alpha_{O}^{\sigma_{3}} p_{O i}^{1-\sigma_{3}}\right)^{1 /\left(1-\sigma_{3}\right)}
$$

At the third stage, the maximum problem for the demand of composite goods is solved (Eq. (A13)).

$$
\begin{aligned}
\max _{\left\{x_{L i}, x_{T i}\right\}} & x_{A i}=\left\{\alpha_{L} x_{L i}{ }^{\left(\sigma_{2}-1\right) / \sigma_{2}}+\alpha_{T} x_{T i}^{\left(\sigma_{2}-1\right) / \sigma_{2}}\right\}^{\sigma_{2} /\left(\sigma_{2}-1\right)} \\
\text { s.t. } & p_{L i} x_{L i}+p_{T i} x_{T i} \leq I_{2 i}
\end{aligned}
$$


The solution of Eq. (A13) is shown as Eq. (A14).

$x_{h i}=\left(\frac{\alpha_{h}}{p_{h i}}\right)^{\sigma_{2}} \frac{I_{2 i}}{\alpha_{L}^{\sigma_{2}} p_{L i}^{1-\sigma_{2}}+\alpha_{T}^{\sigma_{2}} p_{T i}^{1-\sigma_{2}}} \quad(h=L, T)$

The maximum demand of composite goods $\left(\mathrm{x}^{*}{ }_{\mathrm{Ai}}\right)$ is shown as Eq. (A15).

$x_{A i}^{*}=\left(\alpha_{L}^{\sigma_{2}} p_{L i}^{1-\sigma_{2}}+\alpha_{T}^{\sigma_{2}} p_{T i}^{1-\sigma_{2}}\right)^{1 /\left(\sigma_{2}-1\right)} \cdot I_{2 i}$

Thus the price of composite goods $\left(p_{A i}\right)$ is shown as Eq. (A16).

$p_{A i}=\left(\alpha_{L}^{\sigma_{2}} p_{L i}^{1-\sigma_{2}}+\alpha_{T}^{\sigma_{2}} p_{T i}^{1-\sigma_{2}}\right)^{1 /\left(1-\sigma_{2}\right)}$

At the fourth stage, the maximum problem for the utility is solved (Eq. (A17)).

$$
\begin{aligned}
\max _{\left\{x_{G i}, x_{A i}\right\}} & u_{i}=\left\{\alpha_{G} x_{G}{ }^{\left(\sigma_{1}-1\right) / \sigma_{1}}+\alpha_{A} x_{A i}^{\left(\sigma_{1}-1\right) / \sigma_{1}}\right\}^{\sigma_{1} /\left(\sigma_{1}-1\right)} \\
\text { s.t. } & p_{G i} x_{G i}+p_{A i} x_{A i} \leq I_{i}
\end{aligned}
$$

The solution of Eq. (A17) is shown as Eq. (A18).

$$
x_{l i}=\left(\frac{\alpha_{l}}{p_{l i}}\right)^{\sigma_{1}} \frac{I_{i}}{\alpha_{G}^{\sigma_{1}} p_{G i}^{1-\sigma_{1}}+\alpha_{A}^{\sigma_{1}} p_{A i}^{1-\sigma_{1}}} \quad(l=A, G)
$$

The maximum utility $\left(u^{*}\right)$ is shown as Eq. (A19).

$$
u_{i}^{*}=\left(\alpha_{G}^{\sigma_{1}} p_{G i}^{1-\sigma_{1}}+\alpha_{A}^{\sigma_{1}} p_{A i}^{1-\sigma_{1}}\right)^{1 /\left(\sigma_{1}-1\right)} \cdot I_{i}
$$

By integrating the solutions of five maximization problems at four stages, the final optimal demands of general goods $\left(x_{G i}^{*}\right)$, optimal demand of land $\left(x_{L i}^{*}\right)$, and optimal demand of car trips, public transport trips, and walking trips $\left(x^{*}{ }_{m i}\right)$ at maximum utility are shown as Eq. (A20), Eq. (A21), and Eq. (A22).

$$
\begin{aligned}
& x_{G i}^{*}=\left(\frac{\alpha_{G}}{p_{G i}}\right)^{\sigma_{1}} \frac{I_{i}}{\alpha_{G}^{\sigma_{1}} p_{G i}^{1-\sigma_{1}}+\alpha_{A}^{\sigma_{1}} p_{A i}^{1-\sigma_{1}}} \\
& x_{L i}^{*}=\left(\frac{\alpha_{L}}{p_{L i}}\right)^{\sigma_{2}} \frac{I_{2 i}}{\alpha_{L}^{\sigma_{2}} p_{L i}^{1-\sigma_{2}}+\alpha_{T}^{\sigma_{2}} p_{T i}^{1-\sigma_{2}}}=\left(\frac{\alpha_{L}}{p_{L i}}\right)^{\sigma_{2}} \frac{I_{i}}{\alpha_{L}^{\sigma_{2}} p_{L i}^{1-\sigma_{2}}+\alpha_{T}^{\sigma_{2}} p_{T i}^{1-\sigma_{2}}}\left(1-\frac{p_{G i}}{\alpha_{G}^{\sigma_{1}} p_{G i}^{1-\sigma_{1}}+\alpha_{A}^{\sigma_{1}} p_{A i}^{1-\sigma_{1}}}\right)
\end{aligned}
$$




$$
\begin{aligned}
& x_{m i}^{*}=\left(\frac{\alpha_{m}}{p_{m i}}\right)^{\sigma_{4 k}} \alpha_{k}^{\sigma_{3}} \alpha_{T}^{\sigma_{2}} \alpha_{A}^{\sigma_{1}}\left(\alpha_{m}^{\sigma_{4 k}} p_{m i}^{1-\sigma_{4 k}}+\alpha_{n i}^{\sigma_{4 k}} p_{n i}^{1-\sigma_{4 k}}\right)^{\frac{\sigma_{4 k}-\sigma_{3}}{1-\sigma_{4 k}}} \\
& \left\{\begin{array}{l}
\alpha_{P}^{\sigma_{3}}\left(\alpha_{W}^{\sigma_{4 \rho}} p_{W i}^{1-\sigma_{4 \rho}}+\alpha_{C 1}^{\sigma_{4 p}} p_{C 1 i}^{1-\sigma_{4 \rho}}\right)^{1-\sigma_{3}} \\
+\alpha_{O}^{\sigma_{3}}\left(\alpha_{M}^{\sigma_{40}} p_{M i}^{1-\sigma_{40}}+\alpha_{C 2}^{\sigma_{40}} p_{C 2 i}^{1-\sigma_{40}}\right)^{-\sigma_{3}}
\end{array}\right\}^{\frac{\sigma_{3}-\sigma_{2}}{1-\sigma_{3}}} \\
& \left\{\begin{array}{l}
\alpha_{L}^{\sigma_{2}} p_{L 1}^{1-\sigma_{2}}+\alpha_{T}^{\sigma_{2}}\left(\alpha_{P}^{\sigma_{3}}\left(\alpha_{W}^{\sigma_{4 \rho}} p_{W i}^{1-\sigma_{4 \rho}}+\alpha_{C 1}^{\sigma_{4 \rho}} p_{C 1 i}^{1-\sigma_{4 \rho} \rho}\right)^{1-\sigma_{3}}\right. \\
\left.+\alpha_{O}^{\sigma_{3}}\left(\alpha_{M}^{\sigma_{40}} p_{M i}^{1-\sigma_{40}}+\alpha_{C 2}^{\sigma_{40}} p_{C 2 i}^{1-\sigma_{4} \rho}\right)^{1-\sigma_{3}}\right)^{\frac{\sigma_{2}-\sigma_{1}}{1-\sigma_{2}}}
\end{array}\right\}^{1-\sigma_{2}} \\
& \left\{\begin{array}{l}
\alpha_{G}^{\sigma_{1}} p_{G}^{1-\sigma_{1}}+\alpha_{A}^{\sigma_{1}}\left\{\alpha_{L}^{\sigma_{2}} p_{L 1}^{1-\sigma_{2}}+\alpha_{T}^{\sigma_{2}}\left\{\alpha_{P}^{\sigma_{3}}\left(\alpha_{W}^{\sigma_{4 p}} p_{W i}^{1-\sigma_{4 p}}+\alpha_{C 1}^{\sigma_{4 p}} p_{C 1 i}^{1-\sigma_{4 p} p}\right)^{1-\sigma_{3}}\right.\right. \\
\left.\left.+\alpha_{O}^{\sigma_{3}}\left(\alpha_{M}^{\sigma_{40}} p_{M i}^{1-\sigma_{40}}+\alpha_{C 2}^{\sigma_{40}} p_{C 2 i}^{1-\sigma_{40}}\right)^{1-\sigma_{3}}\right\}^{1-\sigma_{2}}\right\}^{\frac{1-\sigma_{1}}{1-\sigma_{2}}}
\end{array}\right\}^{-1} I_{i} \\
& m=C_{1}, W, k=P ; n=C_{2}, M, k=O \\
& \text { or } m=C_{2}, M, k=O ; n=C_{1}, W, k=P
\end{aligned}
$$

\section{References}

[1] Manoj M, Verma A, Navyatha M. Commute travel and its effect on housing tenure choice of males and females living in the urban and rural areas of Bangalore city in India. Journal of Transport Geography 2015; 45: 62-9.

[2] Jenks M, Williams K, Burton E. Achieving Sustainable Urban Form. E\&FN Spon, London, NewYork, 2000.

[3] Grazi F, VandenBergh JCJM, VanOmmeren JN. An empirical analysis of urban form, transport, and global warming. Energy 2008; 29: 97-122.

[4] Burton E, Jenks M, Williams K. The compact city: a sustainable urban form? Taylor \& Francis, 2004.

[5] Yin Y, Mizokami S, Aikawa K. Compact development and energy consumption: Scenario analysis of urban structures based on behavior simulation. Applied Energy 2015; 159, 449-457.

[6] Bouchair A, Tebbouche H, Hammouni A, Lehtihet MC, Blibli M. Compact Cities as a Response to the Challenging Local Environmental Constraints in Hot Arid Lands of Algeria. Energy Procedia 2013; 42: 493-502.

[7] Yamagata Y, Seya H. Simulating a future smart city: An integrated land use-energy model. Applied Energy 2013; 112: 1466-1475. [8] Wiedenhofer D, Manfred L, Steinberger JK. Energy requirements of consumption: Urban form, climatic and socio-economic factors, rebounds and their policy implications. Energy Policy 2013; 63: 696-707.

[9] Fang C, Wang S, Li G. Changing urban forms and carbon dioxide emissions in China: A case study of 30 provincial capital cities. Applied Energy 2015; 158: 519-531.

[10] Yin Y, Mizokami S, Maroyama T. An analysis of the influence of urban form on energy consumption by individual consumption behaviors from a microeconomic viewpoint. Energy Policy 2013: 61, 909-919.

[11] Von Thunen JH. Der isolierte Staat in beziehung auf Landwirtschaft und Nationalokonomie, Gustav Fisher, Stuttgart. English edition: The isolated state (trans: Wartenburg CM (1966), edited by Hall P). Oxford: Pergamon. 1826.

[12] Alonso W. Location and Land Use. Harvard University Press, Cambridge, 1964.

[13] Train KE. Discrete Choice Methods with Simulation. Cambridge University Press, New York, 2003.

[14] Sorrentino A, Meenar R, Lambert J, Wargod T. Housing location in a Philadelphia metro watershed: Can profitable be green? Landscape and Urban Planning 2014; 125: 188-206.

[15] Cao X. Is alternative development undersupplied? Examination of residential preferences and choices of Northern California movers. Transportation Research Record 2008; 2077: 97-105. 
[16] Lewis PG, Baldassare M. The complexity of public attitudes toward compact development. Journal of the American Planning Association 2010; 76: 219-37.

[17] Yang Y, Kelly ON. Understanding factors affecting people's attitudes toward living in compact and mixed-use environments: a case study of a New Urbanist project in Eugene, Oregon, USA. Journal of Urbanism: International Research on Place making and Urban Sustainability 2014; 7(1): 1-22.

[18] Elizabeth C, Delmelle, Zhou Y, Thill JC. Densification without Growth Management? Evidence from Local Land Development and Housing Trends in Charlotte, North Carolina, USA. Sustainability 2014; 6(6): 975-3990.

[19] Howley P. Attitudes towards compact city living: Towards a greater understanding of residential behavior. Land Use Policy 2009; 26: 792-98.

[20] Wu WJ, Zhang WZ, Dong G. Determinant of residential location choice in a transitional housing market: Evidence based on micro survey from Beijing. Habitat International 2013; 39: 16-24.

[21] Torres I, Greene M, Ortúzar JdeD. Valuation of Housing and Neighborhood Attributes for City Centre Location: A Case Study in Santiago. Habitat International 2013; 39: 62-74.

[22] Liao FH, Farber S, Ewing R. Compact development and preference heterogeneity in residential location choice behavior: A latent class analysis. Urban Studies 2015; 52(2): 314-37.

[23] Stephan A, Crawford R H, Myttenaere. A comprehensive assessment of the life cycle energy demand of passive houses. Applied Energy 2013; 112: 23-34.

[24] Kragh J, Rose J. Energy renovation of single-family houses in Denmark utilizing long-term financing based on equity. Applied Energy 2011; 88(6): 2245-253.

[25] Xu X, Culligan PJ, Taylor JE. Energy Saving Alignment Strategy: Achieving energy efficiency in urban buildings by matching occupant temperature preferences with a building's indoor thermal environment. Applied Energy 2014; 123: 209-219.

[26] Kragh K, Rose J. Energy renovation of single-family house in Denmark utilizing long-term financing based on equity. Applied Energy 2011; 6: 2245-2253.

[27] Hamilton IG, Steadman PJ, Bruhns H, Summerfield AJ, Lowe R. Energy efficiency in the British housing stock: Energy demand and the Homes Energy Efficiency Database. Energy Policy 2013; 60: 46280.

[28] Chel A, Tiwari GN. Thermal performance and embodied energy analysis of a passive house - Case study of vault roof mud-house in India. Applied Energy 2009; 86: 1956-969.

[29] Stephan A, Robert H, Myteenaere K. A comprehensive assessment of the life cycle energy demand of passive houses. Applied Energy 2013; 112: 23-34.

[30] Hachem C, Athienitis A, Fazioc P. Energy performance enhancement in multistory residential buildings. Applied Energy 2014; 116: 9-19.

[31] Ujihara $\mathrm{T}$, Abe $\mathrm{H}$, Fujikawa K. Construction of smart shrink model for eco-compact city implementation and applicability. Civil Engineering Planning Studies 2013; 45:106. (in Japanese)

[32] Hartwick J, Schweizer U, Varaiya P. Comparative statics of a residential economy with several classes. Journal of Economic Theory 1976; 13: 396-413.

[33] Wu J. Environmental amenities, urban sprawl, and community characteristics. Journal of Environmental Economics and Management 2006; 52: 7-547.

[34] Jaeger W. K. Determinants of urban land market outcomes: Evidence from California. Land Use Policy 2013; 30(1): 966-973.

[35] Matsuo Y. A study on the energy consumption of walking, IEEJ, Tokyo, in December 2013. (in Japanese) 


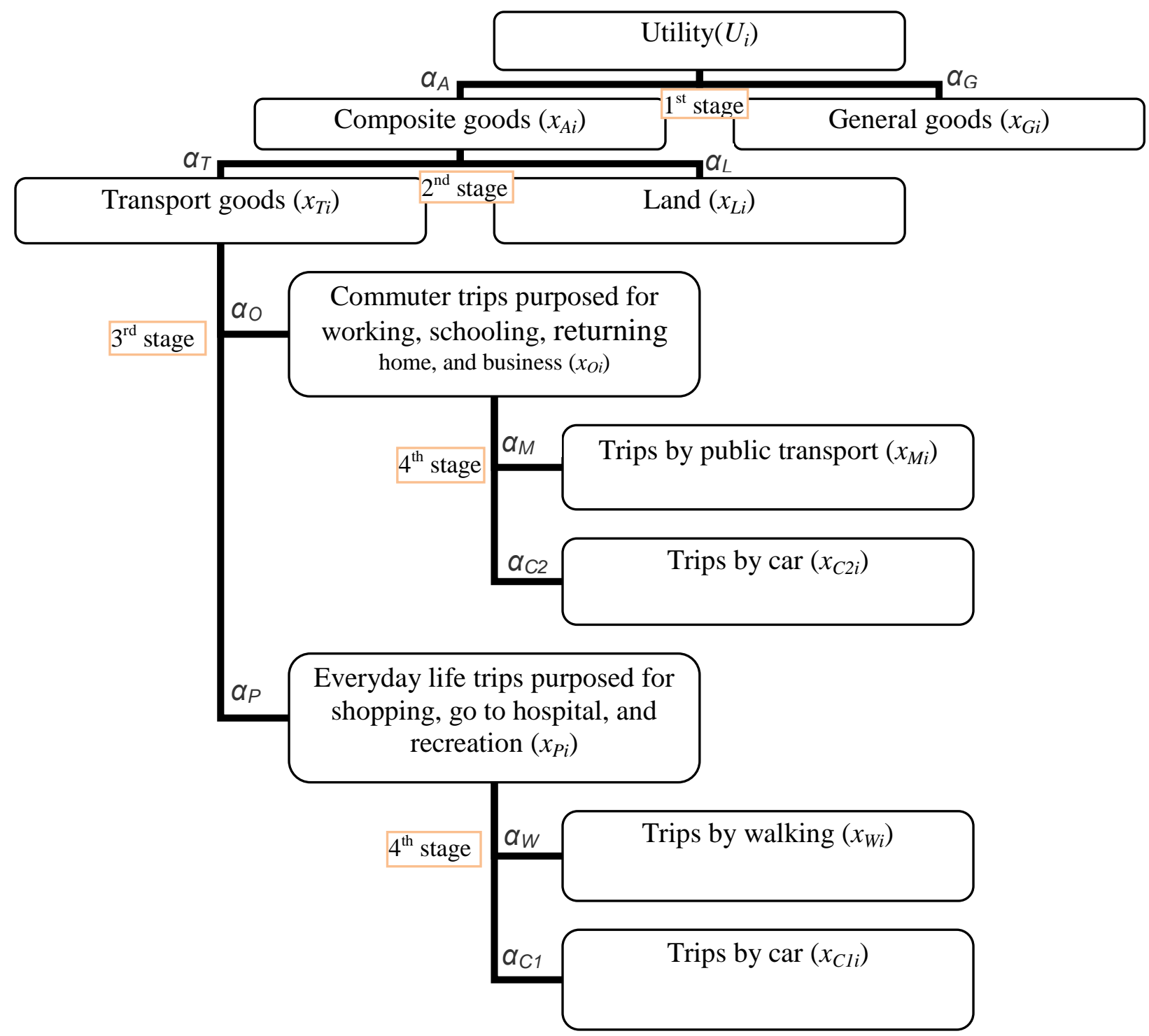

Fig. 1 The nested structure of utility function 

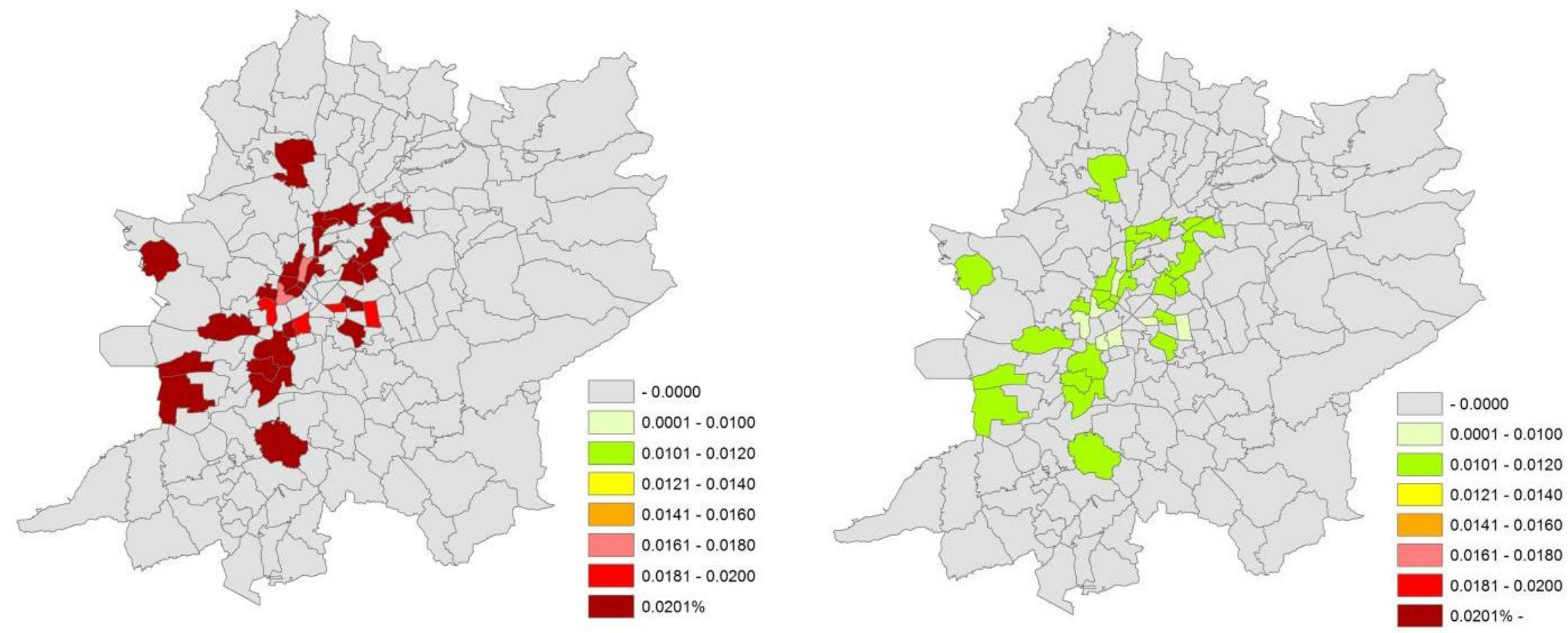

Fig.2.a Population change rate of P1-A-10000

Fig.2.b Population change rate of P1-A-5000 

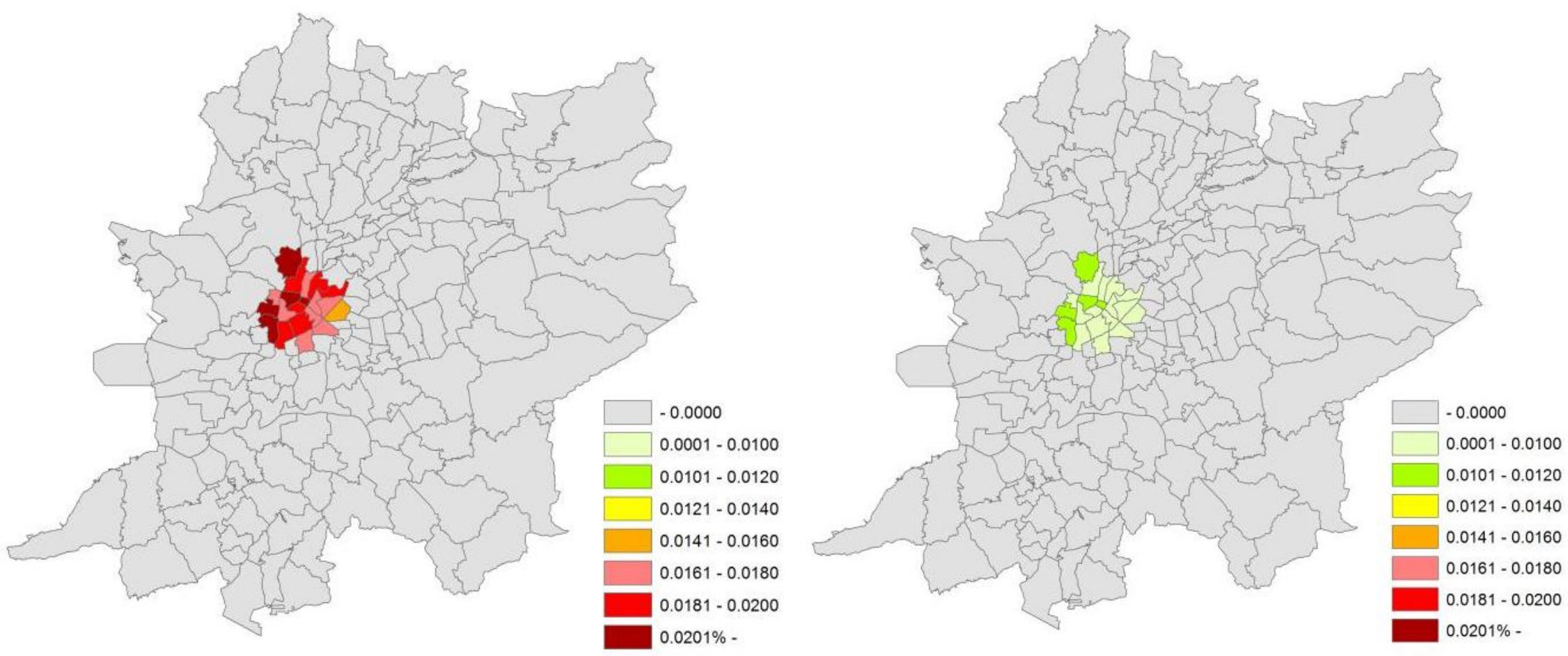

Fig.3.a Population change rate of P1-B-10,000

Fig.3.b Population change rate of P1-B-5000 


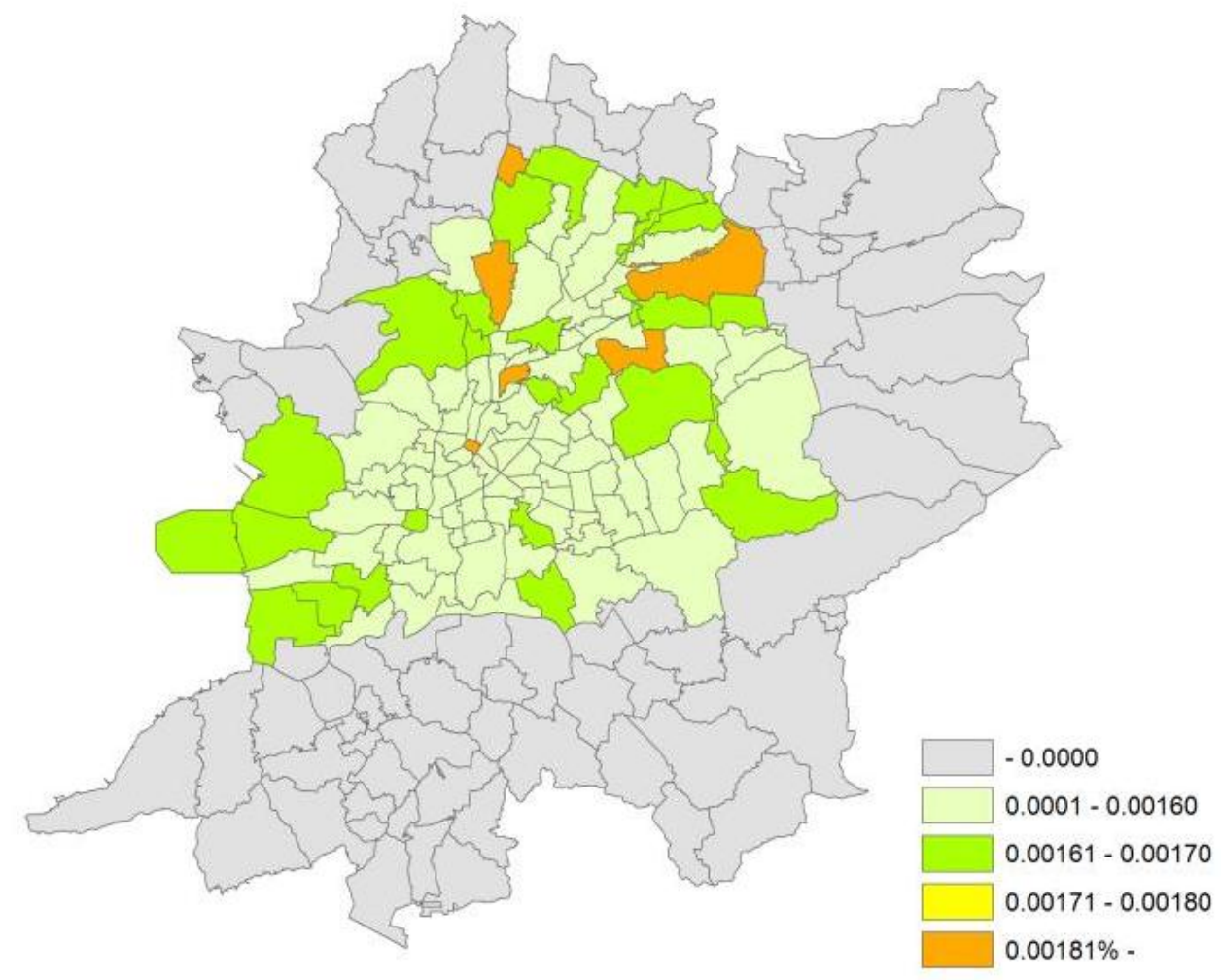

Fig.4. Population change rate of P2 


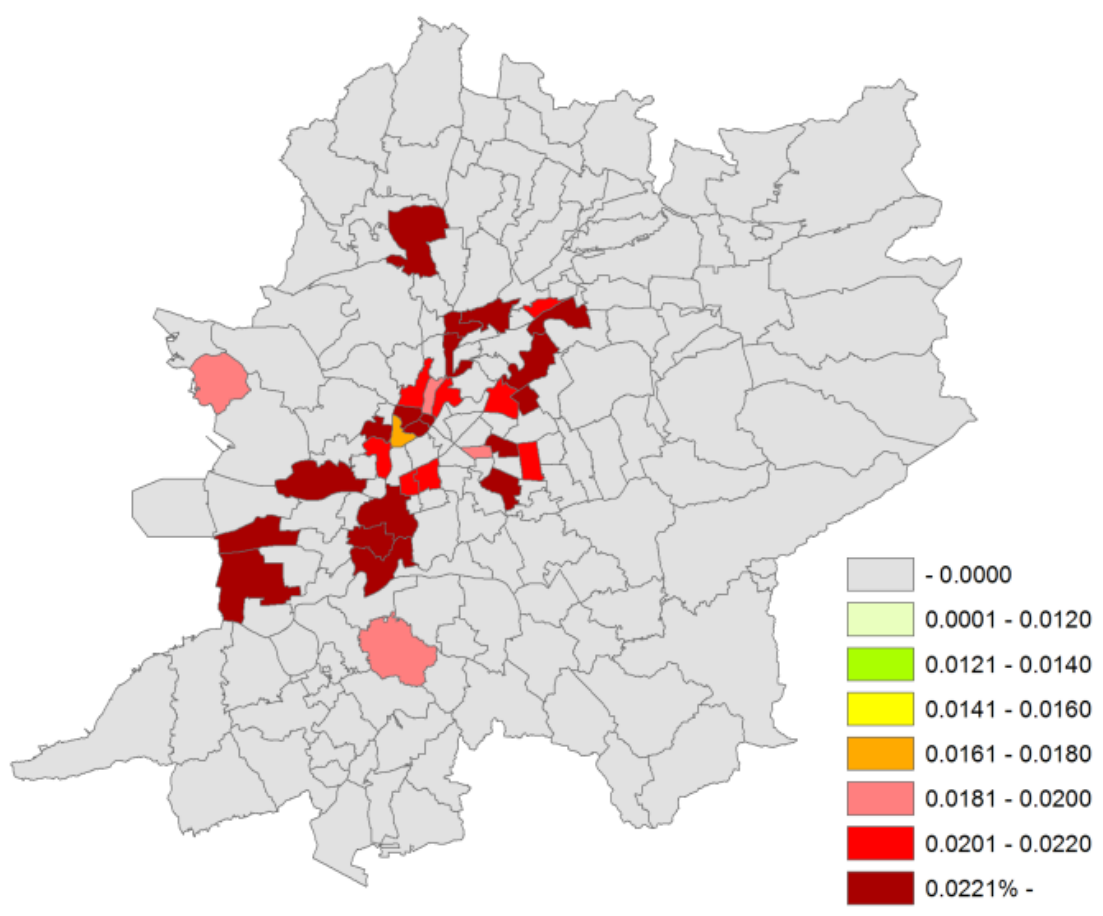

b

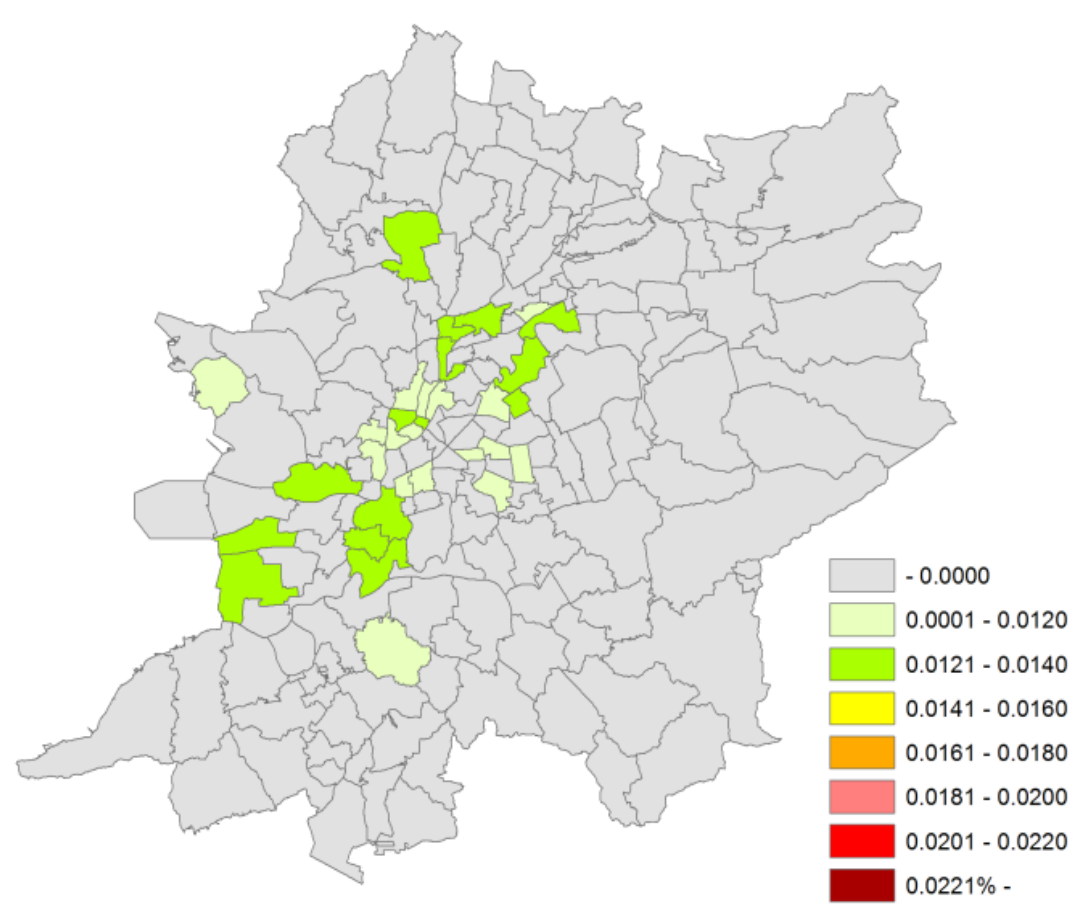

Fig.5.a Population change rate of P3-A-10000

Fig.5.b Population change rate of P3-A-5000 
a

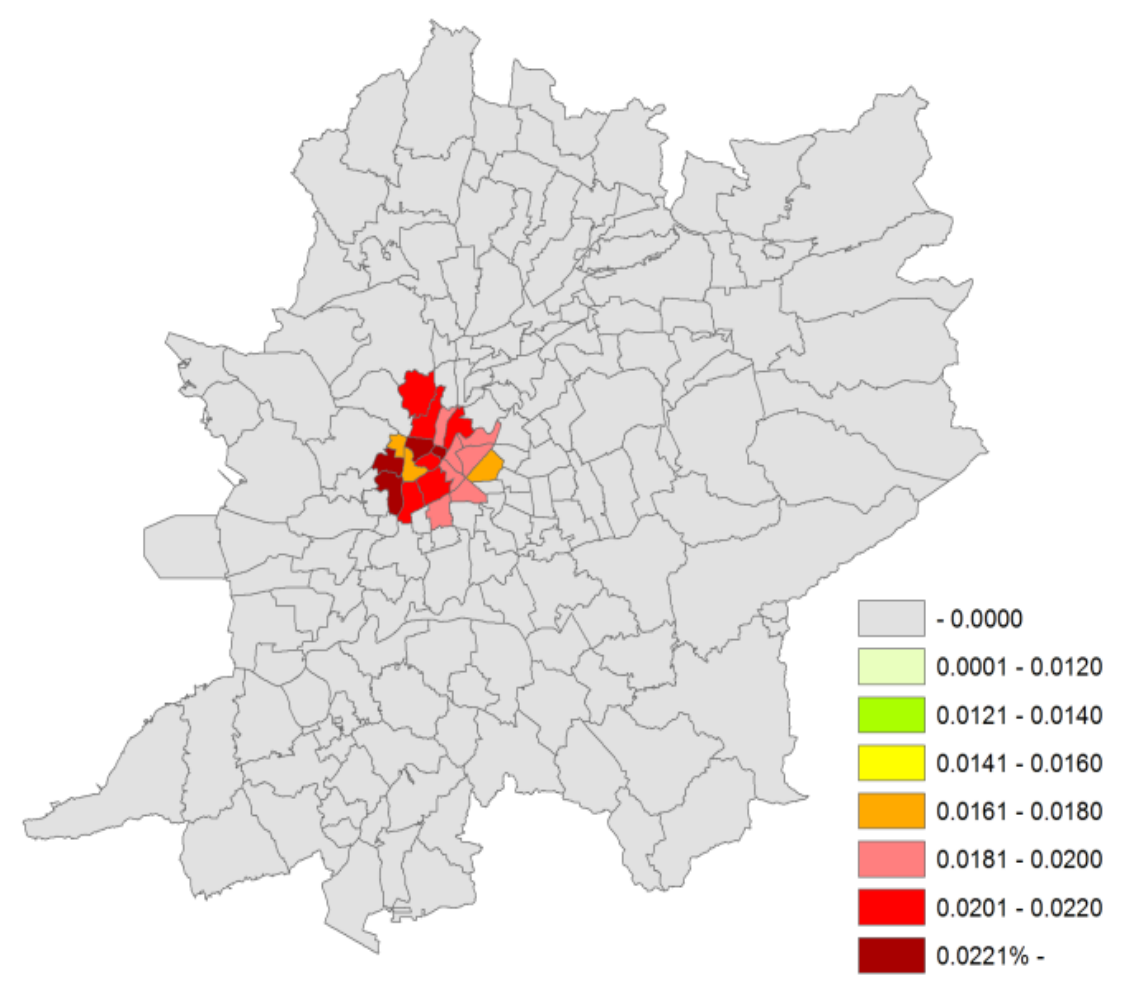

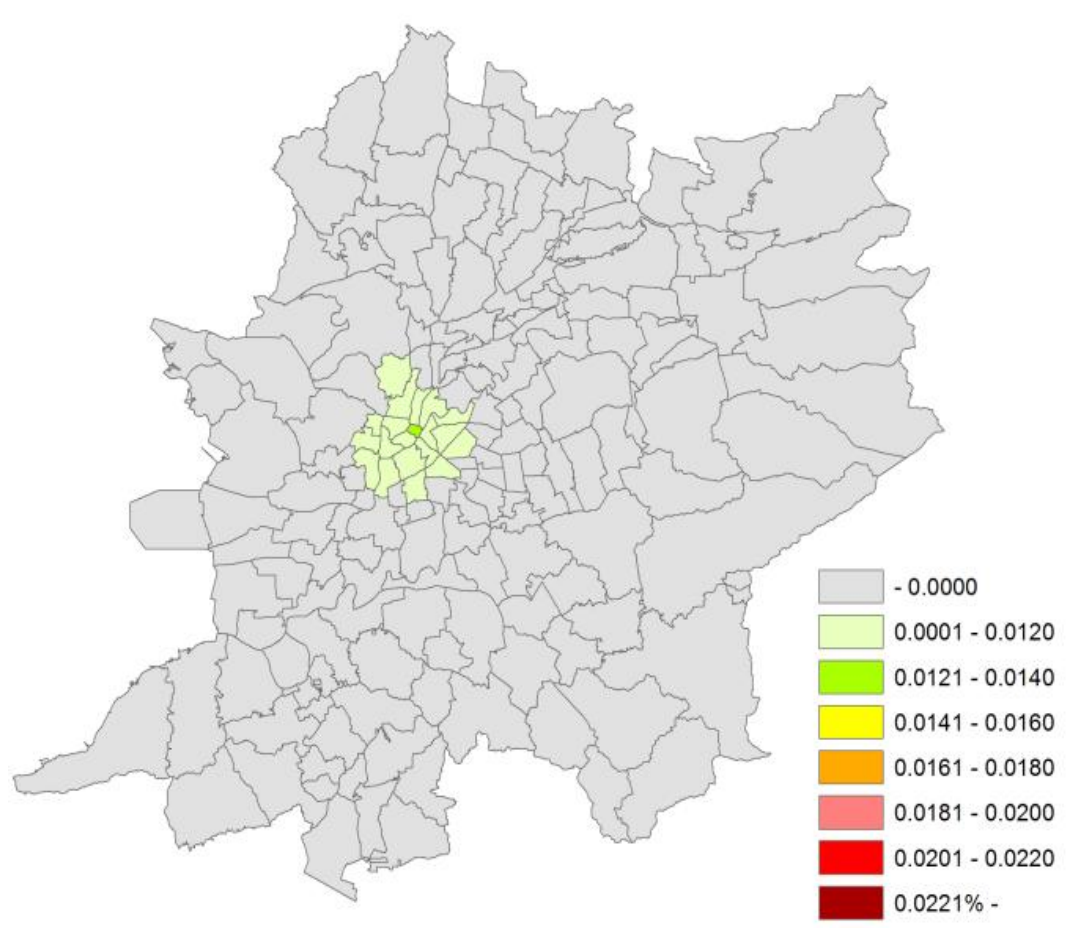

Fig.6.a Population change rate of P3-B-10000 Fig.6.b Population change rate of P3-B-5000 